\title{
Exploiting the Metal-Chelating Properties of the Drug Cargo for In Vivo Positron Emission Tomography Imaging of Liposomal Nanomedicines
}

Edmonds, Scott; Volpe, Alessia; Shmeeda, Hilary; Parente-Pereira, Ana C.; Radia, Riya; Baguña-Torres, Julia; Szanda, Istvan; Severin, Gregory; Livieratos, Lefteris; Blower, Philip J.

Total number of authors:

14

Published in:

A C S Nano

Link to article, DOI:

10.1021/acsnano.6b05935

Publication date:

2016

Document Version

Publisher's PDF, also known as Version of record

Link back to DTU Orbit

Citation (APA):

Edmonds, S., Volpe, A., Shmeeda, H., Parente-Pereira, A. C., Radia, R., Baguña-Torres, J., Szanda, I., Severin, G., Livieratos, L., Blower, P. J., Maher, J., Fruhwirth, G. O., Gabizon, A., \& T.M. de Rosales, R. (2016).

Exploiting the Metal-Chelating Properties of the Drug Cargo for In Vivo Positron Emission Tomography Imaging of Liposomal Nanomedicines. A C S Nano, 10(11), 10294-10307. https://doi.org/10.1021/acsnano.6b05935

\section{General rights}

Copyright and moral rights for the publications made accessible in the public portal are retained by the authors and/or other copyright owners and it is a condition of accessing publications that users recognise and abide by the legal requirements associated with these rights.

- Users may download and print one copy of any publication from the public portal for the purpose of private study or research.

- You may not further distribute the material or use it for any profit-making activity or commercial gain

- You may freely distribute the URL identifying the publication in the public portal 


\title{
Exploiting the Metal-Chelating Properties of the Drug Cargo for In Vivo Positron Emission Tomography Imaging of Liposomal Nanomedicines
}

\author{
Scott Edmonds, ${ }^{\dagger}$ Alessia Volpe, ${ }^{\dagger}$ Hilary Shmeeda, ${ }^{\ddagger}$ Ana C. Parente-Pereira, ${ }^{\S}$ Riya Radia, ${ }^{\dagger,}, \|$
} Julia Baguña-Torres, ${ }^{\dagger}$ Istvan Szanda, ${ }^{\dagger}$ Gregory W. Severin, ${ }^{\perp}$ Lefteris Livieratos, ${ }^{\dagger}$ Philip J. Blower, ${ }^{\dagger}$ John Maher, ${ }^{\S}$ Gilbert O. Fruhwirth, ${ }^{\dagger}$ Alberto Gabizon, ${ }^{\ddagger}$ and Rafael T. M. de Rosales ${ }^{*}$,

\footnotetext{
†Division of Imaging Sciences \& Biomedical Engineering, King's College London, London SE1 7EH, United Kingdom †Oncology Institute, Shaare Zedek Medical Center and Hebrew University-School of Medicine, Jerusalem 9103102, Israel

${ }^{\S}$ Division of Cancer Studies, King's College London, London SE1 1UL, United Kingdom

"Department of Chemistry, King's College London, London SE1 1DB, United Kingdom

${ }^{\perp}$ The Hevesy Lab, Technical University of Denmark, 4000 Roskilde, Denmark
}

\section{Supporting Information}

ABSTRACT: The clinical value of current and future nanomedicines can be improved by introducing patient selection strategies based on noninvasive sensitive whole-body imaging techniques such as positron emission tomography (PET). Thus, a broad method to radiolabel and track preformed nanomedicines such as liposomal drugs with PET radionuclides will have a wide impact in nanomedicine. Here, we introduce a simple and efficient PET radiolabeling method that exploits the metal-chelating properties of certain drugs (e.g., bisphosphonates such as alendronate and anthracyclines such as doxorubicin) and widely used ionophores to achieve excellent radiolabeling yields, purities, and stabilities with ${ }^{89} \mathrm{Zr},{ }^{52} \mathrm{Mn}$, and ${ }^{64} \mathrm{Cu}$, and without the requirement of modification of the nanomedicine components. In a model of metastatic breast
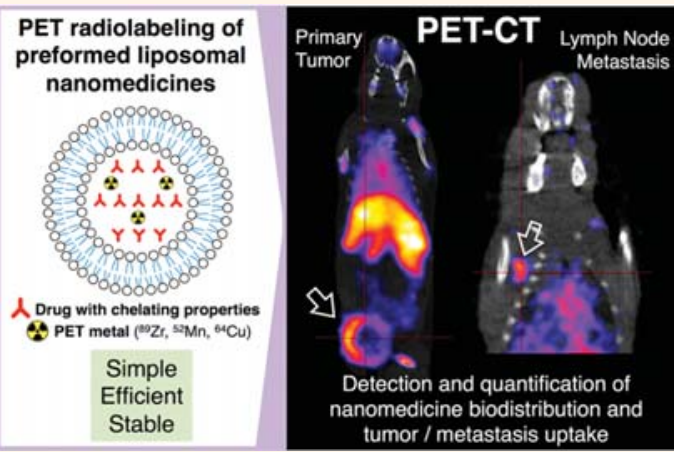
cancer, we demonstrate that this technique allows quantification of the biodistribution of a radiolabeled stealth liposomal nanomedicine containing alendronate that shows high uptake in primary tumors and metastatic organs. The versatility, efficiency, simplicity, and GMP compatibility of this method may enable submicrodosing imaging studies of liposomal nanomedicines containing chelating drugs in humans and may have clinical impact by facilitating the introduction of image-guided therapeutic strategies in current and future nanomedicine clinical studies.

KEYWORDS: nanomedicine, PET imaging, tumor, metastasis, drug delivery, liposomes
$\mathrm{D}$ espite the potential advantages of nanomedicines to improve drug delivery, ${ }^{1}$ they have so far only made a modest clinical impact to date with applications in a limited set of indications and without major improvements over conventional chemotherapies. ${ }^{2}$ Their effect in preventing or diminishing potential toxic side effects of the encapsulated drug payloads has been more pronounced, due to differential drug release in target and nontarget sites. For example, Doxil/ Caelyx - a PEGylated (stealth) liposome containing doxorubicin-has shown equal or slightly superior efficacy to conventional chemotherapy in AIDS-related Kaposi's sarcoma, ovarian cancer, breast cancer, and multiple myeloma while, importantly, abolishing or greatly attenuating the often dose- limiting cardiotoxicity of an equivalent amount of nonencapsulated doxorubicin. ${ }^{3}$ Hence, most nanomedicines with clinical approval today are used as second-line treatments or as part of combination therapies with the major advantage of lower side effects.

In addition to the difficulties of delivering drug nanocarriers to specific tissues in vivo, ${ }^{4,5}$ a major factor that contributes to the failure of nanomedicines to show their full potential in the

Received: September 2, 2016

Accepted: October 12, 2016

Published: October 26, 2016 
A

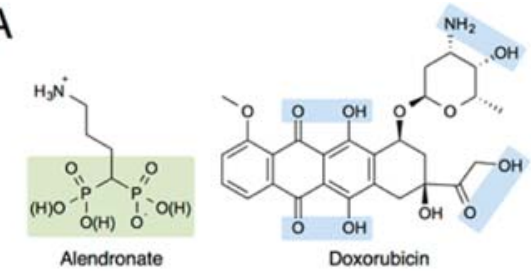

B

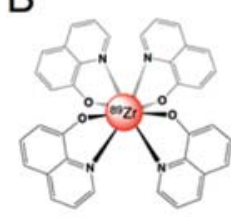

${ }^{89} \mathrm{Zr}(8 \mathrm{HQ})_{4}$

C

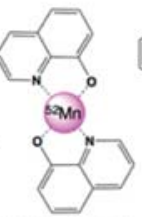

${ }^{52} \mathrm{Mn}(8 \mathrm{HQ})_{2}$

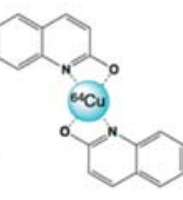

${ }^{64} \mathrm{Cu}(2 \mathrm{HQ})_{2}$

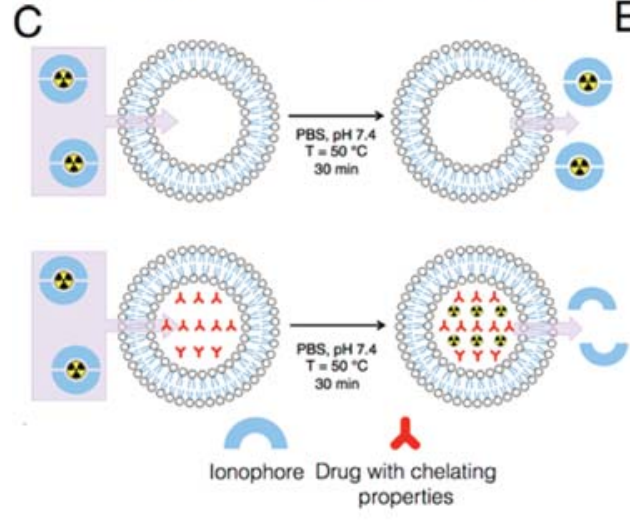

D

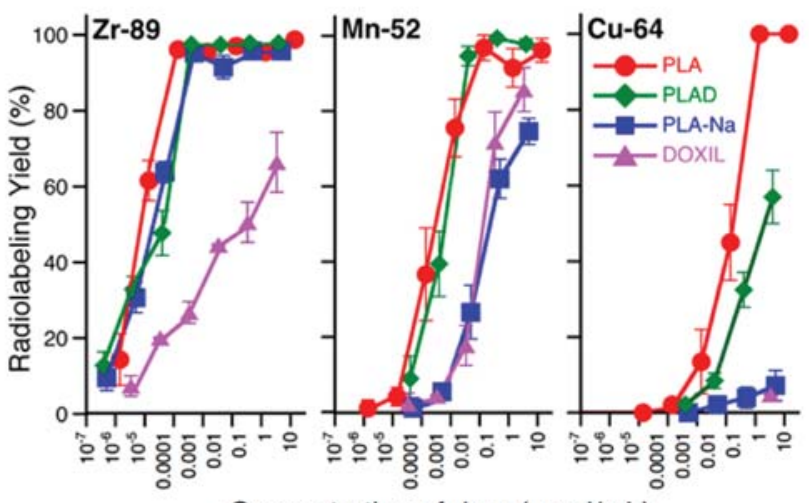

E

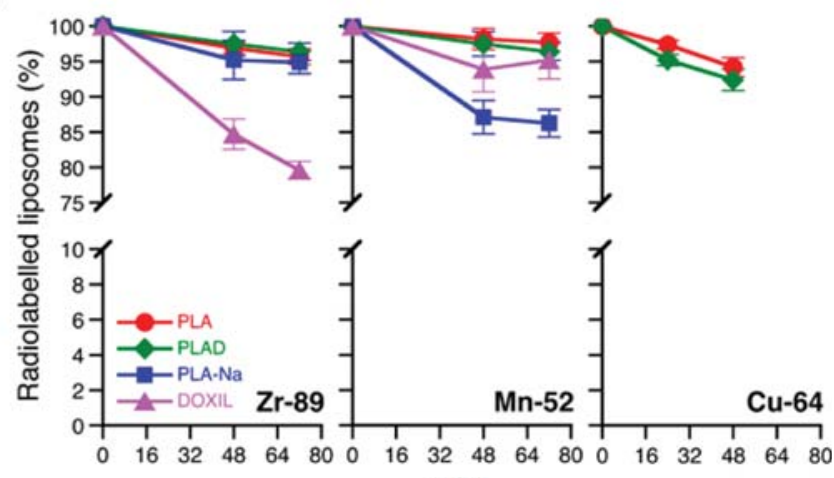

$\mathrm{t}$ (h)

Figure 1. Liposomal nanomedicine PET radiolabeling method. (A) Chemical structure of drugs explored in this study, with metal-binding motifs highlighted in color. (B) Radiometal-ionophore complexes used to radiolabel liposomal nanomedicines: $8 \mathrm{HQ}=8$-hydroquinoline; $2 \mathrm{HQ}=2$-hydroxyquinoline. (C) Schematic representation of the liposome radiolabeling method. Top: Incubation of empty liposomes, lacking encapsulated drug, do not radiolabel after incubating with the radiometal-ionophore complex in PBS or saline at $50{ }^{\circ} \mathrm{C}$ for 30 min. Bottom: Drug-loaded liposomes efficiently radiolabel under the same conditions. (D) Radiolabeling yields of different liposomes with different PET radiometals and at different liposome concentrations $(n=3)$. Note the $x$-axis is in log scale. (E) Serum stabilities after incubating liposomes in human serum at $37{ }^{\circ} \mathrm{C}$ for up to $72 \mathrm{~h}\left({ }^{89} \mathrm{Zr}\right.$, $\left.{ }^{52} \mathrm{Mn}\right)$ or $48 \mathrm{~h}\left({ }^{64} \mathrm{Cu}\right)(n=3)$.

clinic is patient and disease heterogeneity, ${ }^{6}$ as recently demonstrated in cancer patients. Thus, PEGylated liposomes, known to accumulate in solid tumors due to the enhanced permeation and retention (EPR) effect, did not accumulate in tumors at the same level neither in patients with the same nor in patients with different cancers. ${ }^{7}$ This highlights the clinical need to assess which patient group is most likely to accumulate high amounts of the nanomedicine of interest and hence benefit maximally from nanomedicinal treatment and to do so as early as possible in the treatment regimen. Such a personalized medicine approach may allow nanomedicines, alone or in combination with other therapies, to demonstrate their full clinical potential. ${ }^{6,8-10}$

Of the several clinically available noninvasive imaging techniques that would allow such a treatment response prediction tool in the context of nanomedicines, positron emission tomography (PET) is the only one that allows quantitative analysis of biodistribution with exquisite sensitivity (signal/background ratios) and adequate spatial/temporal resolution at the whole-body level. Radiolabeling of liposomal nanomedicines with radionuclides detectable by other nuclear imaging techniques such as single-photon emission computed tomography (SPECT) or planar imaging has been successfully used to study their biodistribution in preclinical and clinical studies. $^{8,9,11}$ SPECT imaging, however, suffers from lower sensitivity and temporal/spatial resolution than PET. Radiolabeling of liposomal drugs with PET isotopes has been explored to a much lesser extent by using radiolabeled lipids or by introduction of exogenous chelators in the intraliposomal space/phospholipid bilayer. ${ }^{12-23}$ Both strategies can be useful in the preclinical setting but represent a significant translational barrier for clinical imaging, as liposome modification can lead to changes in biodistribution, regulatory barriers, and the requirement of customized liposome manufacture. To minimize this barrier, an ideal radiolabeling method would work on preformed liposomal nanomedicines (without changes in the manufacture) containing approved components and using clinical radiolabeling reagents and methods. In addition, radiochemical purities of $>95 \%$ (as required for most radiopharmaceuticals) should be achieved and ideally from high radiolabeling yield reactions ( $>95 \%$ ), hence avoiding the requirement for purification steps. A move in this direction was recently made by Abou et al. by exploiting the oxygen-rich nature of the phospholipid hydrophilic heads and the oxophilicity of ${ }^{89} \mathrm{Zr}$ but suffering from modest stability in biological media. ${ }^{24}$ Moreover, high specific activities (i.e., radioactivity per amount of nanomedicine) should be achieved, allowing the radiolabeling of subtherapeutic amounts of 
nanomedicine and hence microdosing PET studies (defined as $1 \%$ of the therapeutic dose).

We noticed that many drugs of clinical interest in nanomedicine have metal-binding motifs (Figure $1 \mathrm{~A}$ and Figure S1). Hence, we hypothesized that preformed liposomal nanomedicines containing such drugs could be efficiently radiolabeled with metallic PET isotopes such as ${ }^{89} \mathrm{Zr}\left(t_{1 / 2}=\right.$ $78.4 \mathrm{~h}),{ }^{52} \mathrm{Mn}\left(t_{1 / 2}=134.2 \mathrm{~h}\right)$, and ${ }^{64} \mathrm{Cu}\left(t_{1 / 2}=12.7 \mathrm{~h}\right)$, by using well-established metal ionophores (Figure 1B,C). Furthermore, the high concentration of metal-binding drug molecules inside the liposome and the protective effect of the phospholipid bilayer from plasma protein transchelation should result in high radiolabeling yields, specific activities, and stabilities compared to previously reported methods. This strategy would allow the simple radiolabeling and PET imaging of many current and future liposomal nanomedicines and facilitate the introduction of treatment response prediction tools based on PET in the clinical setting. Here, we demonstrate and discuss the feasibility and effectiveness of this method, as well as its advantages and limitations, and show its utility for detecting and quantifying the biodistribution of a liposomal nanomedicine containing an aminobisphosphonate in vivo.

\section{RESULTS}

Liposomal Drug PET Radiolabeling Method Development. Radiolabeling development was performed using radiometal-ionophore complexes and a PEGylated liposome loaded with an aminobisphosphonate, alendronate (ALD, Figure 1A). This liposomal formulation is referred to as PLA. An aminobisphosphonate was selected as the radionuclidebinding drug of choice to develop this method for two reasons: (i) known ability to act as metal chelators to form inert coordination complexes with zirconium, ${ }^{25}$ copper, ${ }^{26}$ and manganese; ${ }^{26}$ and (ii) demonstrated anticancer activity and $\gamma-\delta$ T-cell immunotherapy sensitizing properties. ${ }^{27-29}$ An ionophore was required to transport the radionuclide through the PEGylated lipid bilayer. We selected hydroxyquinoline (8HQ) and 2-hydroxyquinoline (2HQ) for their known properties to transport metal ions across lipid bilayers. ${ }^{14,30,31}$ The effects of temperature and incubation times were studied. Excellent radiolabeling yields (RLYs) and purities of $>95 \%$ were obtained with ${ }^{89} \mathrm{Zr}(8 \mathrm{HQ})_{4},{ }^{52} \mathrm{Mn}(8 \mathrm{HQ})_{2}$, and ${ }^{64} \mathrm{Cu}-$ $(2 \mathrm{HQ})_{2}$ (Figure $\left.1 \mathrm{~B}\right)$, after being incubated with PLA in PBS at $50{ }^{\circ} \mathrm{C}$ with shaking for $30 \mathrm{~min}$ (Figure 1C). These reaction conditions did not change the physicochemical properties of the liposomes, as assessed by dynamic light scattering (DLS) and $\zeta$-potential measurements, pre- and post-incubation (Table $\mathrm{S} 1$ ). Lower temperatures and incubation times resulted in lower RLYs.

Radiolabeling Depends on the Presence and Concentration of the Encapsulated Drug, Its Counterion, and the Radionuclide Used. To probe the versatility of this radiolabeling method, we tested it with three positron-emitting metals $\left({ }^{89} \mathrm{Zr},{ }^{52} \mathrm{Mn}\right.$, and $\left.{ }^{64} \mathrm{Cu}\right)$ and five different PEGylated liposomes. These liposomes had identical/near-identical physicochemical properties (phospholipid composition, hydrodynamic size, and $\zeta$-potential) but contained different drugs/ combination of drugs (ALD (PLA); ALD + doxorubicin (PLAD; $4 \mu \mathrm{mol} / \mathrm{mL}$ ALD $/ 3 \mu \mathrm{mol} / \mathrm{mL}$ doxorubicin); sodium salt of ALD (PLA-Na); doxorubicin (Doxil), or empty (PLACEBO)). The involvement of the encapsulated drug in the radiolabeling process was confirmed by attempting the radiolabeling of PLACEBO liposomes. Hence, using the abovementioned optimized conditions, PLACEBO liposomes were not labeled (RLYs < 5\%) with any of the radionuclides explored in this work (Figure 1C). Drug-loaded liposomes, however, were radiolabeled in a drug-concentration-dependent manner (Figure 1D and Table S4). RLYs obtained with ${ }^{89} \mathrm{Zr}$ and ${ }^{52} \mathrm{Mn}$ were very high over a broader drug concentration range compared to ${ }^{64} \mathrm{Cu}$, spanning several orders of magnitude. Remarkably high radiochemical specific activities were achieved, particularly with ${ }^{89} \mathrm{Zr}$-PLA $\left({ }^{89} \mathrm{Zr}: 154 \pm 75 \mathrm{GBq} / \mu \mathrm{mol}\right.$ encapsulated drug; $38 \pm 17 \mathrm{GBq} / \mu \mathrm{mol}$ lipid; $n=3)$. The nature of the drug and the presence of a coordinating counterion such as sodium, where relevant (PLA-Na, where the counterion is sodium instead of ammonium, present in PLA/PLAD/Doxil) affect RLYs, further confirming their involvement. To study the effect of the lipid membrane composition in RLYs, we attempted the radiolabeling of PROMITIL (PEGylated liposomal mitomycin C prodrug). ${ }^{32}$ This liposome does not contain encapsulated drug, and in contrast to the other liposomes used in this study, its lipid bilayer includes $10 \%$ of a lipophilic prodrug of mitomycin C. Radiolabeling was compared with an identical formulation to PROMITIL that had been loaded with ALD (PROMITILALD; $6.7 \mu \mathrm{mol} / \mathrm{mL}$ ALD). Interestingly, radiolabeling with ${ }^{89} \mathrm{Zr}(8 \mathrm{HQ})_{4}$ resulted in a RLY of $47.9 \pm 4.1 \%, n=3$ for PROMITIL and $93.5 \pm 1.0 \%, n=3$ for PROMITIL-ALD. The relatively high RLY of PROMITIL compared to that of PLACEBO liposomes $(48 \% v s<5 \%)$ is likely to be the result of the presence of the lipophilic prodrug and retention of the highly lipophilic ${ }^{89} \mathrm{Zr}(8 \mathrm{HQ})_{4}$ complex within the bilayer since the labeling was not stable as confirmed by complete transchelation to serum proteins after incubation in human serum. In contrast, radiolabeled PROMITIL-ALD showed high in vitro serum stability (vide infra), further confirming the requirement of the encapsulated drug.

In Vitro Stability of Radiolabeled Liposomal Nanomedicines in Human Serum. The stability of the radiometal-liposome complexes in human serum was studied over $72 \mathrm{~h}\left({ }^{89} \mathrm{Zr},{ }^{52} \mathrm{Mn}\right)$ or $48 \mathrm{~h}\left({ }^{64} \mathrm{Cu}\right)$ by incubation at $37{ }^{\circ} \mathrm{C}$ and analyzed using size-exclusion chromatography. Radiolabeled liposomes were highly stable in vitro under these conditions (Figure 1E). It should be noted that since the circulation halflife of nanomedicines that exploit the EPR effect such as stealth liposomes (e.g., Doxil/Caelyx) in humans is in the 50-80 h range, ${ }^{33}$ serum stabilities of $\geq 80 \%$ at $72 \mathrm{~h}$ at these conditions are considered as excellent. Collectively, very low leakage of radioactivity after $72 \mathrm{~h}$ of incubation was found for all radiometals with liposomes containing the strongly metalchelating drug ALD $(95.0 \pm 3.7 \%, n=24)$. The degree of serum stability with doxorubicin showed a higher dependency on the radiometal, with stabilities after $72 \mathrm{~h}$ of incubation ranging from $79.6 \pm 1.2 \%\left(n=3,{ }^{89} \mathrm{Zr}\right)$ to $95.2 \pm 2.7 \%,(n=3$, ${ }^{52} \mathrm{Mn}$ ). Interestingly, lower in vitro serum stabilities were consistently observed with liposomal drug-radiometal combinations that do not achieve high RLYs with micromolar amounts of encapsulated drug (i.e., ${ }^{89} \mathrm{Zr}$-Doxil and ${ }^{52} \mathrm{Mn}$-PLA$\mathrm{Na}$ ). In addition, ${ }^{89} \mathrm{Zr}$-PROMITIL (radiolabeled at $40 \% \mathrm{RLY}$ ) was not stable in serum after $48 \mathrm{~h}$ incubation $(1.0 \pm 0.3 \%, n=$ 3 ), whereas ${ }^{89} \mathrm{Zr}$-PROMITIL-ALD showed excellent stability $(86.9 \pm 3.2 \%, n=3)$. The lack of serum stability for ${ }^{89} \mathrm{Zr}$ PROMITIL is probably due to nonspecific weak binding of the radiometal to the liposome due to the absence of intraliposomal drug/chelator. 


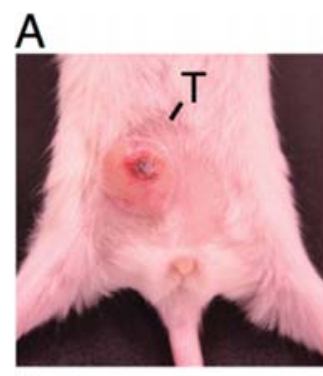

B
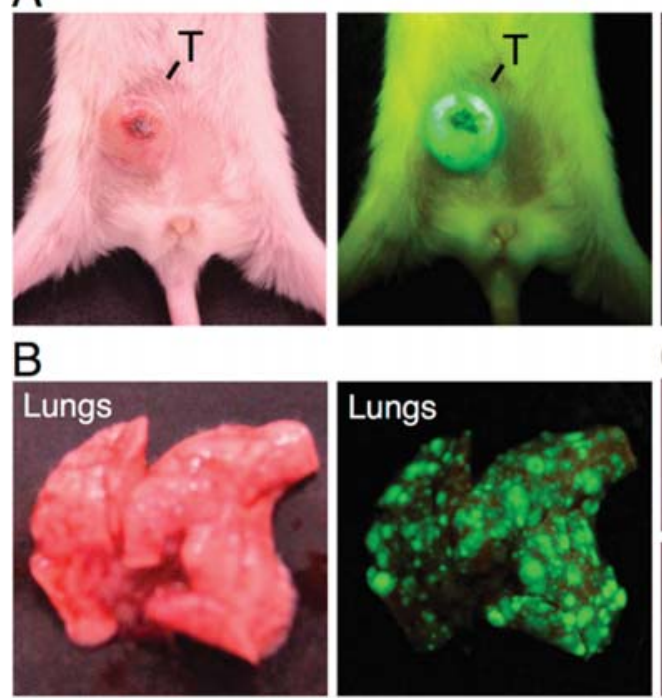

D

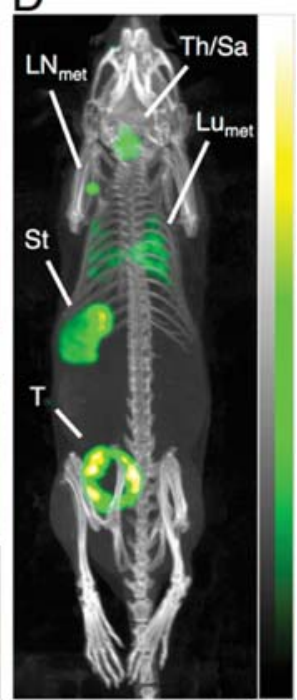

Figure 2. 3E.A.NT/NSG mouse model of metastatic mammary carcinoma. (A) Photographs of a representative primary tumor (T) in the mammary gland of NSG mice under white light (left) and under excitation light showing green fluorescence (center) and red fluorescence (right). (B) Lungs under white light (left) and excitation light (right), showing miliary metastatic spread. (C) Top: Metastatic lymph node $\left(\mathrm{LN}_{\text {met }}\right.$ left axial) under white light (left) and excitation light (right) showing the presence of metastasis. Bottom: Nonmetastatic lymph node (LN, left brachial) under white light (left) and excitation light (right) showing the absence of metastasis. (D) Maximum intensity projection SPECT-CT image of 3E.A.NT/NSG mouse $1 \mathrm{~h}$ after injection of $\left[{ }^{99 \mathrm{~m}} \mathrm{TcO}_{4}\right]^{-}(30 \mathrm{MBq})$. Uptake is observed in hNIS-expressing $3 \mathrm{E} . \Delta . \mathrm{NT}$ cells in the primary tumor $(\mathrm{T})$ and metastatic left axillary lymph node $\left(\mathrm{LN}_{\text {met }}\right)$ and lungs $\left(\mathrm{Lu}_{\text {met }}\right)$. Endogenous hNIS-expressing organs such as thyroid $(\mathrm{Th})$, salivary glands $(\mathrm{Sa})$, and stomach $(\mathrm{St})$ are also visible.

Monitoring Liposomal Nanomedicine Distribution in a Metastatic Mammary Carcinoma Model. The biodistribution of the radiolabeled liposomes was monitored using PET imaging with ${ }^{89} \mathrm{Zr}$-PLA in a metastatic mammary carcinoma mouse model (3E.A.NT) established in immunocompromised NSG mice. This cancer model is traceable by SPECT imaging/fluorescence due to a dual-modality reporter gene, the human sodium iodide symporter (hNIS-tagRFP), that allows sensitive detection of viable cancer tissues (primary tumor and metastases) using SPECT imaging with ${ }^{99 m} \mathrm{Tc}$ pertechnetate $\left(\left[{ }^{99} \mathrm{TcO}_{4}\right]^{-}\right)$and fluorescence (GFP/RFP) during dissection and histological studies (Figure 2 and Figure S2). ${ }^{34}$ The imaging protocol was as follows: first, 3E. $\Delta . \mathrm{NT} /$ NSG mice were injected with ${ }^{89} \mathrm{Zr}$-PLA $(4.6 \pm 0.4 \mathrm{MBq}$ in 1.2 $\mu$ mol phospholipid) at $t=0$ followed by PET-CT imaging (liposome biodistribution). The same mice were then injected with $\left[{ }^{99 \mathrm{~m}} \mathrm{TcO}_{4}\right]^{-}(30 \mathrm{MBq})$ and imaged by SPECT-CT (hNISpositive cancer cell biodistribution, vide infra). This process (apart from ${ }^{89} \mathrm{Zr}$-PLA injection that was only performed at $t=0$ h) was repeated at $t=24 \mathrm{~h}, 72 \mathrm{~h}(n=5)$, and $168 \mathrm{~h}(n=1)$. In order to confirm that the presence of ${ }^{99 \mathrm{~m}} \mathrm{Tc}$ was not affecting the quality of the PET study, a series of phantoms were scanned with different amounts of ${ }^{99 \mathrm{~m}} \mathrm{Tc}$ and ${ }^{99 \mathrm{~m}} \mathrm{Tc} /{ }^{89} \mathrm{Zr}$ combinations, confirming that the $2 \mathrm{MBq}$ of ${ }^{99 \mathrm{~m}} \mathrm{Tc}$ that could potentially be present in mice $24 \mathrm{~h}$ after $\left[{ }^{99 \mathrm{~m}} \mathrm{TcO}_{4}\right]^{-}$injection did not affect PET image quality/quantification. We chose ${ }^{89} \mathrm{Zr}$ PLA to validate our method in vivo due to the increasing interest in ${ }^{89} \mathrm{Zr}$ for monitoring long-circulating biomolecules in clinical PET studies, ${ }^{35}$ coupled with the strong metal-chelating properties of $\mathrm{ALD}^{26}$ and its properties as an efficient sensitizer for $\gamma-\delta$ T-cell immunotherapy. ${ }^{29}$ SPECT-CT imaging revealed the location of the primary tumor as well as endogenous hNISexpressing organs such as the thyroid, salivary glands, stomach, and mammary glands (Figure 2D). We also found that this tumor model develops spontaneous metastases in lymph nodes and lungs (Figure 2B-D). CT images revealed a significant increase in tumor volume during the imaging study (from 0.29 $\pm 0.09 \mathrm{~mL}$ at $t=1 \mathrm{~h}$ to $0.75 \pm 0.33 \mathrm{~mL}$ at $t=72 \mathrm{~h}(n=5 ; P=$ 0.017)). Accordingly, the hNIS-positive tumor volume calculated by SPECT increased from $0.19 \pm 0.08 \mathrm{~mL}$ at $t=1$ $\mathrm{h}$ to $0.56 \pm 0.08 \mathrm{~mL}$ at $t=72 \mathrm{~h}$. Using these volumes, we were able to calculate the percentage of necrotic tumor tissue over time, by subtracting the hNIS-positive volume (SPECT) to the total tumor volume (CT), and found no statistically significant changes or trends during the study with an average of $29 \pm 10 \%$ $(n=5)$ necrotic tissue over the $72 \mathrm{~h}$ study.

The PET-CT study (Figure 3A,B and Table S3) was consistent with the stealth properties of PLA, showing mainly blood pool uptake at $t=1 \mathrm{~h}$. On the other hand, a control experiment of free ${ }^{89} \mathrm{Zr}$-alendronate $\left({ }^{89} \mathrm{Zr}\right.$-ALD) resulted in high kidney/renal excretion and bone uptake $1 \mathrm{~h}$ postadministration, as expected for a small molecule bisphosphonate ${ }^{36}$ and/or free ${ }^{89} \mathrm{Zr}^{37}$ (vide infra and Figure S3). The longcirculating nature of ${ }^{89} \mathrm{Zr}$-PLA is also evident from the high signal in the heart during the study (from $31.2 \pm 7.2 \% \mathrm{ID} / \mathrm{mL}$ at $1 \mathrm{~h}$ to $8.32 \pm 0.90 \% \mathrm{ID} / \mathrm{mL}$ at $72 \mathrm{~h})$. The calculated circulation half-life, assuming first-order single-compartment pharmacokinetics, is $15 \mathrm{~h}$, matching that of similar mouse studies with PEGylated liposomal bisphosphonates with identical lipid composition ${ }^{38}$ and other PEGylated liposomes. ${ }^{39}$

The PET imaging study revealed that ${ }^{89} \mathrm{Zr}$-PLA accumulates in the spleen $(22.2 \pm 4.0 \% \mathrm{ID} / \mathrm{mL}$ at $72 \mathrm{~h})$, tumor (nonnecrotic, $12.0 \pm 2.6 \% \mathrm{ID} / \mathrm{mL}$; whole tumor, $9.2 \pm 1.1 \% \mathrm{ID} / \mathrm{mL}$ at $72 \mathrm{~h}$ ), uterus $(9.5 \pm 0.9 \% \mathrm{ID} / \mathrm{mL}$ at $72 \mathrm{~h})$, and bone (femur; $8.4 \pm 1.8 \% \mathrm{ID} / \mathrm{mL}$ at $72 \mathrm{~h}$ ) (Figure $3 \mathrm{~A}, \mathrm{~B}$ and Table S2). We also performed a PET-CT study using ${ }^{64} \mathrm{Cu}$-PLA in an ovarian cancer model (SKOV-3/SCID-Beige) over $48 \mathrm{~h}$ (Figure S4 and Table S3). This study was performed to test the versatility and 


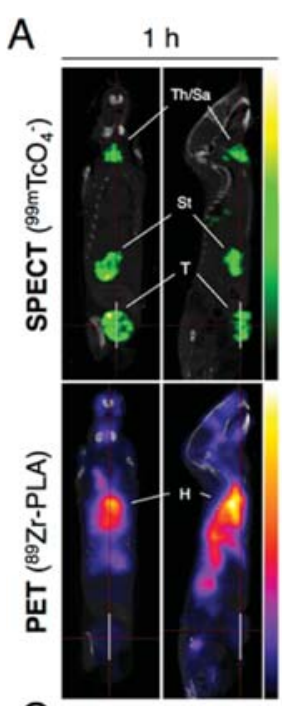

C

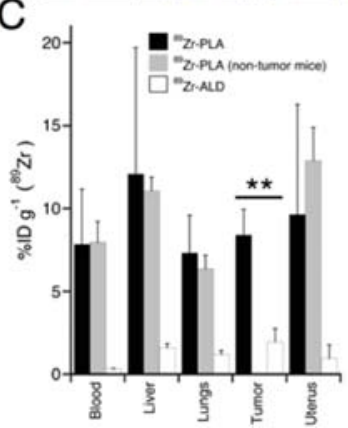

$24 \mathrm{~h}$
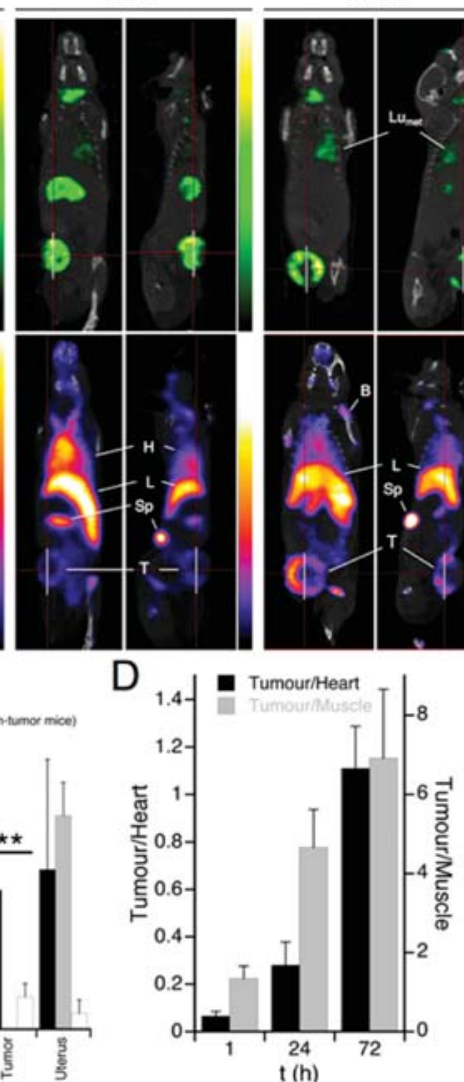

B
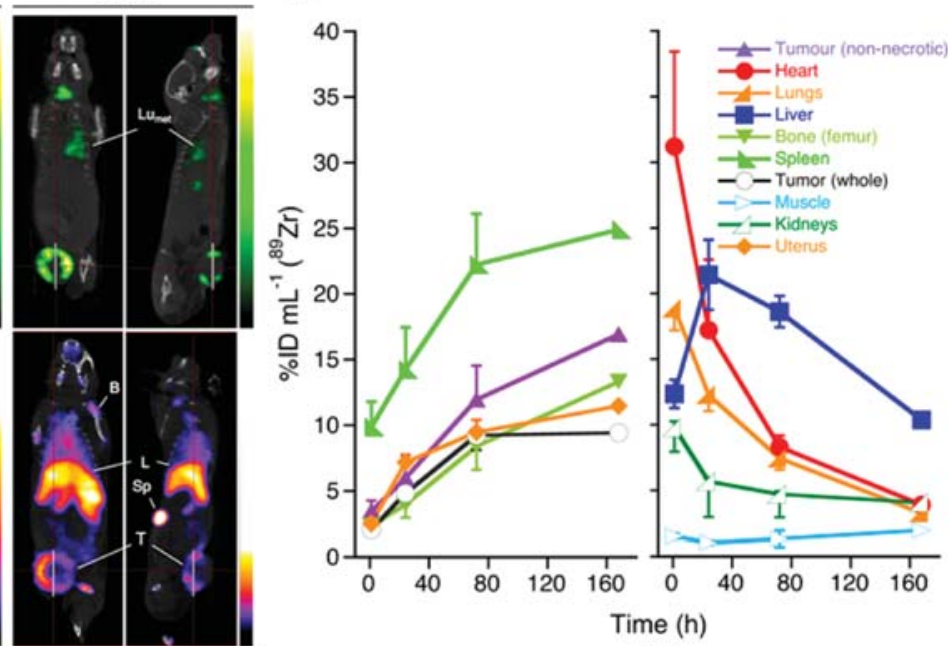

$\mathrm{F}$

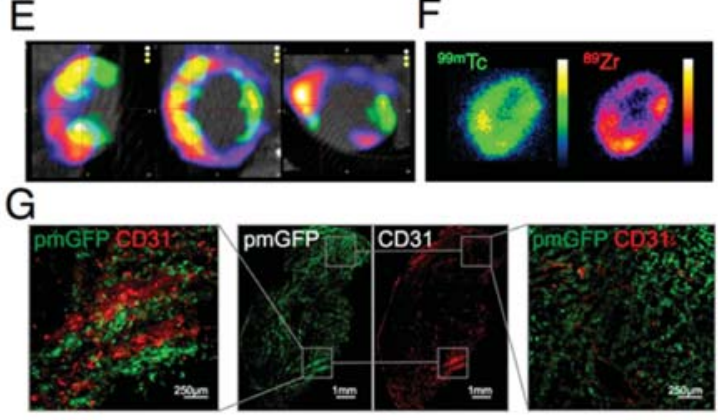

Figure 3. Multimodal imaging study with ${ }^{89} \mathrm{Zr}$-PLA in the 3E.A.NT/NSG mouse model of metastatic breast cancer. (A) Coronal and sagittal SPECT-CT (top) and PET-CT (bottom) images centered at the tumors of the same animal from 1 to $72 \mathrm{~h}$ after injection of ${ }^{89} \mathrm{Zr}-\mathrm{PLA}$ (4.6 $\mathrm{MBq}$ in $1.2 \mu \mathrm{mol}$ lipid). SPECT-CT images show identical biodistribution of $\left[{ }^{99 \mathrm{~m}} \mathrm{TcO}_{4}\right]^{-}$over time with high uptake in endogenous hNISexpressing organs and hNIS-expressing tumor cells in the tumor $(\mathrm{T})$ and metastatic organs $\left(\mathrm{LN}_{\text {met }}\right.$ and $\left.\mathrm{Lu}_{\text {met }}\right)$. PET-CT images show the increasing uptake of ${ }^{89} \mathrm{Zr}$ over time in the primary tumor $(\mathrm{T})$, spleen $(\mathrm{Sp})$, liver $(\mathrm{L})$, and bone (B) and decreasing uptake in blood pool/heart (H). (B) Time-activity curves $\left({ }^{89} \mathrm{Zr}\right)$ based on the preclinical imaging study shown in (a) $(n=5$ from $t=1-72 \mathrm{~h} ; n=1$ at $t=168 \mathrm{~h})$. Organs have been segregated into ascending (left) and descending uptake (right) for clarity. (C) Ex vivo biodistribution graph showing data for

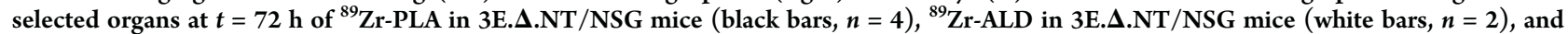
${ }^{89} \mathrm{Zr}$-PLA in non-tumor-bearing NSG mice (gray bars, $n=3$ ). $* * P<0.01$. Two-tailed $t$-test (unpaired). Full ex vivo biodistribution data at $t=$ $72 \mathrm{~h}$ are available in Table 1 . (D) Selected tumor to organ ratios from the ${ }^{89} \mathrm{Zr}$-PLA/3E. $\Delta . \mathrm{NT} / \mathrm{NSG}$ study $(n=4)$ showing an increase over time. (E) Co-registered SPECT-PET-CT images of the primary tumor (from left to right: sagittal, coronal, transverse) showing a high degree of colocalization and heterogeneity of the ${ }^{89} \mathrm{Zr}$ (purple scale) and ${ }^{99} \mathrm{~m}$ Tc signals (green scale) within the non-necrotic rim. (F) Autoradiography images (left, ${ }^{99 \mathrm{~m}} \mathrm{Tc}$; right, ${ }^{89} \mathrm{Zr}$ ) of coronal slice from the same tumor as in (e) showing high degree of colocalization and heterogeneity of both signals. (G) Fluorescence imaging of an adjacent slice of the same tumor as in (e,f) showing both areas of high colocalization of microvasculature (CD31-positive, red) and GFP-positive (green) cancer cells (GFP, left), and low colocalization (right).

capability of our radiolabeling method to track liposomal nanomedicines in other tumor models with different radioisotopes. Results revealed a similar biodistribution profile with long circulation time and high tumor, liver, and spleen uptake at $48 \mathrm{~h}$ but lacking uterus and bone uptake, which can be explained by the different animal model and isotope (vide infra).

Increasing uptake of ${ }^{89} \mathrm{Zr}$-PLA in the tumor over time is consistent with the EPR effect and the long blood half-life of these liposomes and is supported by increasing tumor-tomuscle and tumor-to-heart/blood ratios (Figure 3D). Accumulation of long-circulating liposomes in the spleen is frequently seen with stealth liposomes and reflected by its rising uptake values over time. It is important to note, however, that the values reported for the spleen from the image-based quantification are an underestimate of the real uptake due to the small size of the spleen in young NSG mice $(13 \pm 4 \mathrm{mg} ; n$ =9), which cannot be segmented accurately by CT due its poor soft tissue contrast and the substantial partial volume effect of the PET signal from this organ. Hence, the volume for the spleen used in this calculation was that of the PET signal which results in a significantly smaller uptake value compared to that obtained from the ex vivo biodistribution (Table 1 and Table S2). The uptake in liver followed a different profile to other organs, with an increase for the first $24 \mathrm{~h}$ followed by a decrease. We found a similar liver time-activity profile in the ${ }^{64} \mathrm{Cu}-\mathrm{PLA} / \mathrm{SKOV}-3$ study (Figure S4C and Table S3). This result fits well with the known role of hepatic Kupffer cells in the fast uptake and subsequent metabolism of liposomal nanomedicines, which peaks within the first $24 \mathrm{~h}^{40}$ Accordingly, uptake in bone increases over time as a result of the destruction of ${ }^{89} \mathrm{Zr}$-PLA in the liver and/or after tissue 
Table 1. Ex Vivo Biodistribution Data of ${ }^{89} \mathrm{Zr}$-Labeled PLA or ALD

\begin{tabular}{|c|c|c|c|}
\hline PET tracer & ${ }^{89} \mathrm{Zr}-\mathrm{ALD}$ & ${ }^{89} \mathrm{Zr}-\mathrm{PLA}$ & ${ }^{89} \mathrm{Zr}-\mathrm{PLA}$ \\
\hline $\begin{array}{l}\text { mouse model } \\
\text { (number of animals) }\end{array}$ & $\begin{array}{c}\text { 3E. } \Delta . \mathrm{NT} / \mathrm{NSG} \\
\quad(n=2)\end{array}$ & $\begin{array}{c}\text { 3E. } \Delta . \mathrm{NT} / \mathrm{NSG} \\
\quad(n=4)\end{array}$ & $\begin{array}{l}\text { NSG } \\
(n=3)\end{array}$ \\
\hline organ & \multicolumn{3}{|c|}{$\% \mathrm{ID} / \mathrm{g}($ mean $\pm \mathrm{SD})$ at $72 \mathrm{~h}$ post-injection } \\
\hline kidneys & $11.7 \pm 8.7$ & $3.7 \pm 0.7$ & $4.8 \pm 0.6$ \\
\hline femur & $34.8 \pm 2.8$ & $11.1 \pm 3.1$ & $11.3 \pm 1.1$ \\
\hline muscle & $0.4 \pm 0.1$ & $1.1 \pm 0.8$ & $0.7 \pm 0.1$ \\
\hline heart & $0.52 \pm 0.03$ & $4.3 \pm 1.1$ & $3.2 \pm 0.5$ \\
\hline spleen & $3.6 \pm 1.2$ & $169 \pm 50$ & $137 \pm 5$ \\
\hline blood & $0.33 \pm 0.02$ & $7.8 \pm 3.3$ & $8.0 \pm 1.3$ \\
\hline liver & $1.6 \pm 0.3$ & $12.1 \pm 7.6$ & $11.1 \pm 0.8$ \\
\hline intestines & $0.32 \pm 0.02$ & $2.6 \pm 0.5$ & $2.4 \pm 0.11$ \\
\hline lungs & $1.2 \pm 0.2^{a}$ & $7.3 \pm 2.3^{a}$ & $6.4 \pm 0.8$ \\
\hline \multirow[t]{2}{*}{ lung metastases ${ }^{b}$} & $\mathrm{~N} / \mathrm{C}$ & $\begin{aligned} 12.4 & \pm 4.8 \\
(n & =3)^{c}\end{aligned}$ & N/A \\
\hline & \multicolumn{3}{|c|}{$9.5 \pm 7.0(n=4)$} \\
\hline stomach & $0.16 \pm 0.06$ & $1.9 \pm 0.8$ & $1.0 \pm 0.1$ \\
\hline tumor (whole) & $2.0 \pm 0.8$ & $8.4 \pm 1.6$ & N/A \\
\hline uterus & $0.9 \pm 0.8$ & $9.6 \pm 6.7$ & $13.0 \pm 2.0$ \\
\hline $\begin{array}{l}\text { metastatic lymph } \\
\text { nodes }\left(\mathrm{LN}_{\mathrm{met}}\right)^{a}\end{array}$ & $6.9 \pm 3.5(n=3)$ & $\begin{array}{c}16.3 \pm 7.1 \\
(n=7)\end{array}$ & N/A \\
\hline $\begin{array}{l}\text { normal lymph nodes } \\
\text { (LN) }\end{array}$ & $5.6 \pm 1.5(n=3)$ & $3.8 \pm 2.3(n=4)$ & $\begin{array}{r}5.0 \pm 3.5 \\
(n=3)\end{array}$ \\
\hline
\end{tabular}

${ }^{a}$ Containing metastases as assessed by hNIS-positive SPECT/ fluorescence signal. ${ }^{b}$ Calculated by subtracting the average mass and $\%$ ID of nonmetastatic lungs ( ${ }^{89} \mathrm{Zr}$-PLA/NSG study) to each data from metastatic lungs ( ${ }^{89} \mathrm{Zr}$-PLA/MTLn3E. $\Delta . \mathrm{NT} / \mathrm{NSG}$ study). ${ }^{c}$ Calculated by removing one outlier $(1.0 \% \mathrm{ID} / \mathrm{g})$ that was 8.6 -fold lower than the smallest of the rest of the data points. $\mathrm{N} / \mathrm{A}=$ not applicable; $\mathrm{N} / \mathrm{C}=$ not calculated.

extravasation and release of liposomal contents (free ${ }^{89} \mathrm{Zr}$ or ${ }^{89} \mathrm{Zr}$-ALD) that have high affinity to bone. It should be noted that we did not observe significant bone accumulation in the ${ }^{64} \mathrm{Cu}$-PLA/SKOV-3 study (Table S3), supporting the notion that it is free/nonchelated ${ }^{89} \mathrm{Zr}$, and not ${ }^{89} \mathrm{Zr}$-ALD, that binds to bone. However, the affinity of $\mathrm{Cu}$ (II) toward bisphosphonates is much lower than that of $\mathrm{Zr}(\mathrm{IV})$, and free $\mathrm{Cu}$ (II) would target liver rather than bone once the ${ }^{64} \mathrm{Cu}$ (II)-ALD complex dissociates. We therefore cannot firmly identify the species that are binding to bone in the ${ }^{89} \mathrm{Zr}$ study. Similar bone uptake values have been found with long-circulating $(>24 \mathrm{~h}){ }^{89} \mathrm{Zr}$ labeled antibodies and liposomes, suggesting that these bonetargeting species are nonchelated ${ }^{89} \mathrm{Zr}$ released after liposome disassembly. ${ }^{19,41-43}$ Highly vascular organs such as the lungs and kidneys followed the same decreasing trend in signal as the heart/blood, as expected for long-circulating nanoparticles that are cleared via the reticuloendothelial system (RES). One animal from the group was further imaged at $168 \mathrm{~h}$ to confirm the biodistribution trend. Thus, a significant increase of ${ }^{89} \mathrm{Zr}$ was observed from time point 72 to $168 \mathrm{~h}$ in viable tumor tissue (from $12.0 \pm 2.6$ to $16.9 \% \mathrm{ID} / \mathrm{mL}$ ) and bone (from $8.4 \pm$ 1.8 to $13.3 \% \mathrm{ID} / \mathrm{mL}$ ), as well as a decrease in the liver (from $18.6 \pm 1.2$ to $10.4 \% \mathrm{ID} / \mathrm{mL}$ ) and heart/blood (from $8.3 \pm 0.9$ to $3.9 \% \mathrm{ID} / \mathrm{mL}$ ).

Our SPECT-CT/PET-CT imaging strategy allowed us to coregister the two modalities and study the localization of ${ }^{89} \mathrm{Zr}$ (PLA) and ${ }^{99 \mathrm{~m}} \mathrm{Tc}$ (hNIS tumor cells) in the tumors (Figure 3E,F and Video S1). Both ${ }^{89} \mathrm{Zr}$ and ${ }^{99 \mathrm{~m}} \mathrm{Tc}$ concentrated in the rim of the tumor with high levels of colocalization, particularly in the basal area of the tumor in direct contact with the body of the animal. Co-localization of ${ }^{99 \mathrm{~m}} \mathrm{Tc}$ and ${ }^{89} \mathrm{Zr}$ within the nonnecrotic rim was heterogeneous, and ${ }^{89} \mathrm{Zr}$ (PLA) localization did not always correspond to areas of high ${ }^{99 \mathrm{~m}} \mathrm{Tc}$ uptake. We investigated this observation further using histological studies (vide infra).

Ex Vivo Tissue Distribution Analysis of Radiolabeled Liposomal Nanomedicine. Organ biodistribution data were obtained at the end of the imaging studies $(72 \mathrm{~h})$ to support the imaging-based quantification $(n=4)$ (Table 1, Figure 3C, and Table S2). The results are in close agreement; showing high uptake values in spleen $(169 \pm 49 \% \mathrm{ID} / \mathrm{g})$, liver $(12.1 \pm$ $7.6 \% \mathrm{ID} / \mathrm{g})$, femur $(11.1 \pm 3.1 \% \mathrm{ID} / \mathrm{g})$, uterus $(9.6 \pm 6.7 \% \mathrm{ID} /$ $\mathrm{g})$, and tumor $(8.4 \pm 1.6 \% \mathrm{ID} / \mathrm{g})$. In addition, there was a significant amount of ${ }^{89} \mathrm{Zr}$ in blood $(7.8 \pm 3.3 \% \mathrm{ID} / \mathrm{g})$ and other vascular organs such as the lungs $(7.3 \pm 2.3 \% \mathrm{ID} / \mathrm{g})$. Surprisingly, the ex vivo uptake value measured in lungs was very similar to that from the image-based distribution (7.4 \pm $0.9 \% \mathrm{ID} / \mathrm{mL}$ ). This was unexpected since the large proportion of air in lungs during in the in vivo study should, in principle, result in different $\% \mathrm{ID} / \mathrm{g}$ and $\% \mathrm{ID} / \mathrm{mL}$ values. We believe there are three main factors that could contribute to this unexpected result. First, metastatic lungs had a $c a$. 50\% higher mass compared to normal lungs. Second, there is still a significant amount of circulating ${ }^{89} \mathrm{Zr}$-PLA at this time point, which may contribute to different in vitro/vivo amounts present in the lungs. Lastly, the breathing of mice under general anesthesia is very suppressed, which may result in an overall low lung volume measured.

Two independent ex vivo biodistribution control experiments were performed at $72 \mathrm{~h}$ post-injection to validate the findings of the tumor study with ${ }^{89} \mathrm{Zr}$-PLA. First, a control experiment with ${ }^{89} \mathrm{Zr}$-ALD in tumor-bearing mice assessed the potential contribution of the release of intraliposomal complex/nonchelated ${ }^{89} \mathrm{Zr}$ in the biodistribution data of ${ }^{89} \mathrm{Zr}$-PLA. The results $(n=2)$ showed a significantly different biodistribution profile, consistent with fast-clearing small bisphosphonates and/or unchelated ${ }^{89} \mathrm{Zr}$, with main uptake in bone (i.e., femur) $(34.8 \pm 2.8 v s 11.1 \pm 3.1 \% \mathrm{ID} / \mathrm{g} ; P=0.0008)$ and negligible presence in blood compared to ${ }^{89} \mathrm{Zr}$-PLA $(0.33 \pm 0.02$ vs $7.8 \pm$ $3.3 \% \mathrm{ID} / \mathrm{g} ; P=0.0396)$ at $72 \mathrm{~h}$ after injection. Tumor uptake with ${ }^{89} \mathrm{Zr}$-ALD was surprisingly high $(2.0 \pm 0.8 \% \mathrm{ID} / \mathrm{g})$, but in agreement with recent reports in other murine tumor models using weakly chelated ${ }^{89} \mathrm{Zr}$ (as an oxalate complex), ${ }^{37}$ and significantly lower compared to the ${ }^{89} \mathrm{Zr}$-PLA study ( $8.4 \pm 1.6 \%$ $\mathrm{ID} / \mathrm{g} ; P=0.006)$. We performed a second biodistribution control study with ${ }^{89} \mathrm{Zr}$-PLA in non-tumor-bearing NSG mice of the same age to investigate uterus uptake and as a control for the presence of metastasis in the lungs. We found no significant differences in the \% $\mathrm{ID} / \mathrm{g}$ uptake values of the uterus in comparison with data from the tumor-bearing mice (Figure $3 \mathrm{C}$ and Table 1). This result confirms that uterus uptake is not related to the tumor-bearing condition. Similarly, the presence of miliary metastases in the lungs (as detected by in vivo SPECT/ex vivo fluorescence, Figure $2 \mathrm{~B}, \mathrm{D})$ had no significant effect in the uptake of ${ }^{89} \mathrm{Zr}$-PLA in the lungs $(7.3 \pm 2.3$ for tumor mice vs $6.4 \pm 0.8 \% \mathrm{ID} / \mathrm{g}$ for nontumor mice; $P=0.6)$. The calculated uptake in metastastatic lung tissue, however, is in the range of $9.5 \pm 6.9 \% \mathrm{ID} / \mathrm{g}(n=4)$ to $12.4 \pm 4.8 \% \mathrm{ID} / \mathrm{g}(n$ $=3$, after removing one outlier), which is comparable to those from viable primary tumor $(12.0 \pm 2.6 \% \mathrm{ID} / \mathrm{mL})$ and metastatic lymph nodes $(16.3 \pm 7.1 \% \mathrm{ID} / \mathrm{g}$, vide infra $)$.

Multimodal Imaging Strategy Allows Detection and Quantification of Liposomal Nanomedicine Uptake in 

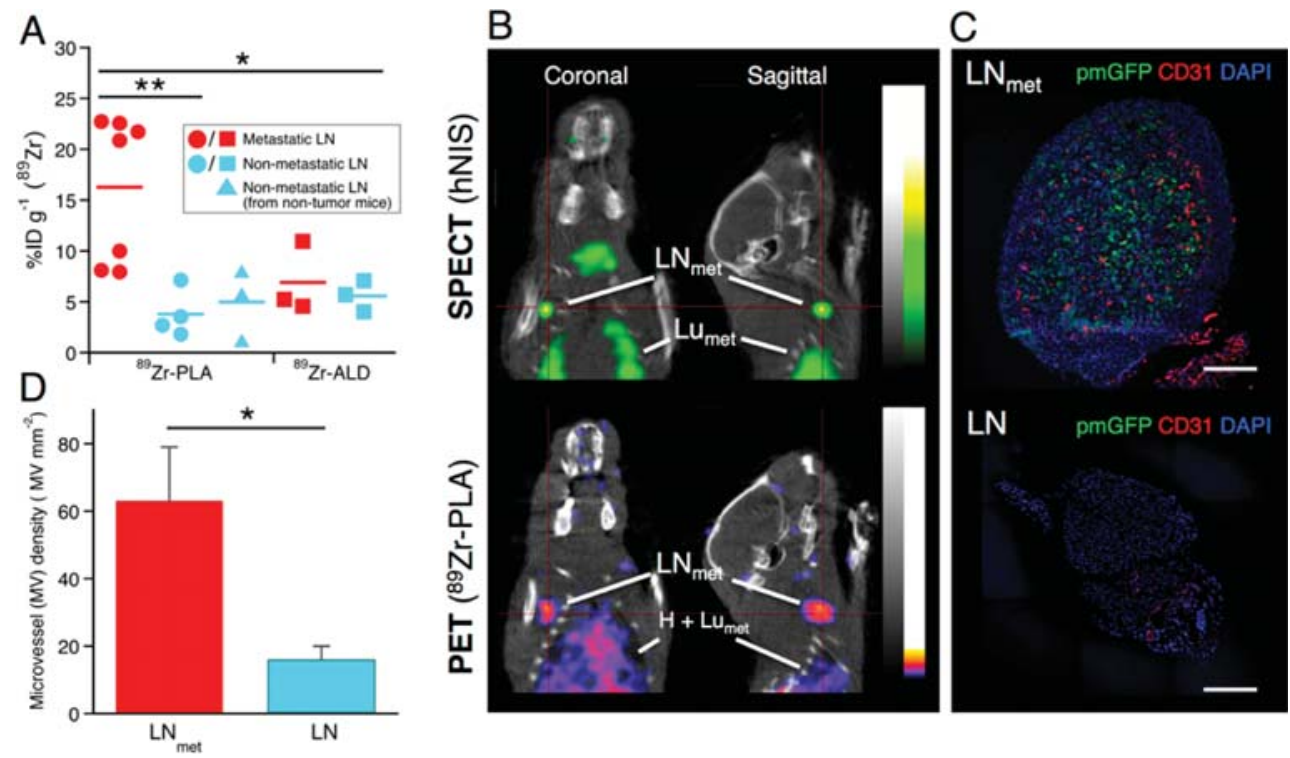

Figure 4. Multimodal imaging data showing the accumulation of ${ }^{89} \mathrm{Zr}$-PLA in metastatic lymph nodes $\left(\mathrm{LN}_{\mathrm{met}}\right)$. (A) Ex vivo biodistribution data

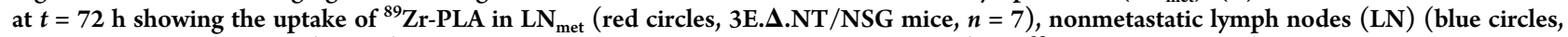

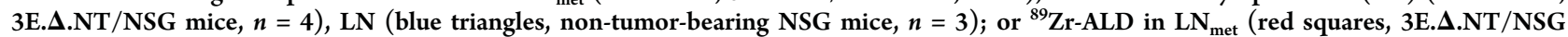

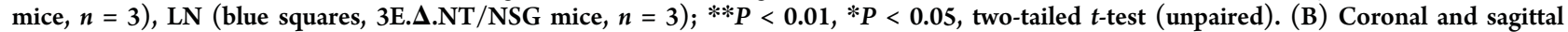
SPECT-CT (top) and PET-CT (bottom) images centered at the $\mathrm{LN}_{\text {met }}$ of same animal from at $72 \mathrm{~h}$ after injection of ${ }^{89} \mathrm{Zr}$-PLA. (C) Fluorescence microscopy images of sections of $\mathrm{LN}_{\text {met }}$ (top) and $\mathrm{LN}$ (left brachial, bottom). A high degree of metastasis (green) and microvasculature density (red) is observed in $\mathrm{LN}_{\mathrm{met}}$ but not in $\mathrm{LN}$. Scale bar is $250 \mu \mathrm{m}$. (D) Quantification of microvasculature density in $\mathrm{LN}_{\text {met }}$ (black bar) and $\mathrm{LN}$ (gray bar) from fluorescence imaging, ${ }^{*} P<0.05$; $t$-test, one-sided, unpaired, mean \pm SEM; $n=2$ ).

Metastatic Lymph Nodes. The presence of the multimodal reporter gene in the 3E. $\Delta . \mathrm{NT}$ cell line allowed the detection by SPECT and optical imaging of spontaneous metastases in the left axillary lymph nodes $(n=4)$ and lungs $(n=4)$ (Figure $2 \mathrm{~B}, \mathrm{C})$ in all the animals studied. Three more lymph nodes in individual mice were identified as metastatic (one left brachial, one right axillary, and one renal). The biodistribution studies also revealed that all the hNIS-positive, and hence metastatic lymph nodes $\left(\mathrm{LN}_{\mathrm{met}}\right)$, had a significant higher accumulation of ${ }^{89} \mathrm{Zr}$-PLA than nonmetastatic lymph nodes (LN) from the same animals $(16.3 \pm 7.1$ vs $3.8 \pm 2.3 \% \mathrm{ID} / \mathrm{g} ; P=0.009)$, or $\mathrm{LN}$ from tumor-free mice $(16.3 \pm 7.1$ vs $5.0 \pm 3.5 \% \mathrm{ID} / \mathrm{g} ; P=0.03)$ (Figure 4A). Using this information, a closer inspection of the PET images revealed that ${ }^{89} \mathrm{Zr}$ was visible in the left axillary $\mathrm{LN}_{\text {met }}$ of mice with highest uptake (Figure 4B). There was no difference in the uptake of ${ }^{89} \mathrm{Zr}-\mathrm{ALD}$ in $\mathrm{LN}_{\text {met }}$ and $\mathrm{LN}(6.9 \pm$ 3.5 vs $5.6 \pm 1.5 \% \mathrm{ID} / \mathrm{g} ; P=0.6)$.

We studied the mechanism of ${ }^{89} \mathrm{Zr}$-PLA uptake in the primary tumor and $\mathrm{LN}_{\text {met }}$ using histology (fluorescence and/or autoradiography). The autoradiographs of ${ }^{99 \mathrm{~m}} \mathrm{Tc}$ distribution in primary tumors were in accordance with the SPECT imaging results, showing the presence of a necrotic core and a mostly viable tumor tissue rim containing the hNIS-expressing cancer cells (Figure 3E,F and Figure S5). The autoradiography with ${ }^{89} \mathrm{Zr}$ was also localized to the tumor rim. Similar to what we found in the SPECT-PET co-registration data, colocalization of ${ }^{99 \mathrm{~m}} \mathrm{Tc}$ and ${ }^{89} \mathrm{Zr}$ within the viable tumor areas was heterogeneous and a strong ${ }^{89} \mathrm{Zr}$ signal did not always correspond to areas of high ${ }^{99 \mathrm{~m}} \mathrm{Tc}$ uptake. Fluorescence microscopy studies on adjacent tumor sections using anti-CD31 antibody and the endogenous signal from hNIS-GFP revealed a high degree of microvascularization in the rim of the tumor and a distribution that did not completely match that of the hNIS-positive cells
(Figure 3g). Since these liposomes accumulate in tumor tissue via the EPR effect, this result provides a potential explanation for the different ${ }^{89} \mathrm{Zr}$ and ${ }^{99 \mathrm{~m}} \mathrm{Tc}$ intratumoral distributions. Similarly, we found a ca. 4-fold higher degree of microvasculature density (CD31) in $\mathrm{LN}_{\text {met }}$ in comparison to that in LN (Figure 4D, $63 \pm 16$ vs $16 \pm 4$ vessels $/ \mathrm{mm}^{2}$; mean \pm SEM; $P=0.0304$; $t$-test, one-sided, unpaired), strongly supporting increased uptake of ${ }^{89} \mathrm{Zr}$-PLA by EPR effect in $\mathrm{LN}_{\text {met }}$.

\section{DISCUSSION}

Our results establish that preformed liposomal nanomedicines, including some currently in clinical use, can be efficiently labeled with PET radiometals and tracked in vivo by exploiting the metal affinity and high concentration of the encapsulated drugs. To date, PET radiolabeling of liposomes has relied on either the introduction of radiolabeled phospholipids or exogenous chelators in the intraliposomal space/phospholipid bilayer. ${ }^{12-23}$ Importantly, our technique allows radiolabeling of preformed liposomal nanomedicines, without modification of their components and without affecting their physicochemical properties. In addition, it achieves high radiolabeling yields, purities, specific activities, and in vitro/vivo stabilities that are at least equal or significantly improved (e.g., specific activity) to previous PET radiolabeling methods. ${ }^{12-23}$

Our method requires the use of hydroxyquinoline ionophores to transport the metallic radionuclides through the lipid bilayer into the intraliposomal space, where the metal exchanges ligand and binds to the encapsulated drug. The use of ionophores was essential for efficient radiolabeling and attempts to label liposomes in its absence, as recently reported for ${ }^{64} \mathrm{Cu},{ }^{20}$ did not work in our hands for any of the radiometals used. $8 \mathrm{HQ}$ however, is extensively used in radiopharmacies for labeling cells with $\gamma$-emitting isotopes and hence does not 
represent a significant barrier for clinical translation ${ }^{30}$ and has been recently been used for labeling cells with ${ }^{89} \mathrm{Zr}^{31} 2 \mathrm{HQ}$ has been previously used to radiolabel with ${ }^{64} \mathrm{Cu}$ liposomes loaded with the chelator DOTA, ${ }^{14}$ while here we report the use of $8 \mathrm{HQ}$ with the PET tracers ${ }^{89} \mathrm{Zr}$ and ${ }^{52} \mathrm{Mn}$.

We tested the radiolabeling method with three different PET radiometals of sufficient radioactive half-life to track longcirculating nanomedicines and four PEGylated liposomes of known/promising preclinical and clinical efficacy. ${ }^{29,33}$ These liposomes contained different combinations of drugs but have identical phospholipid chemical composition and physicochemical properties. The presence of a water-phase encapsulated drug with metal-chelating properties is a requirement for effective labeling, as proven by the lack of efficient and stable radiolabeling in its absence, even when the lipid bilayer contains highly lipophilic components such as the mitomycin $\mathrm{C}$ prodrug.

The high intraliposomal concentration of alendronate or doxorubicin allows for very efficient RLYs over a remarkably wide range of submicromolar drug concentrations (i.e., as much as 5 orders of magnitude with ${ }^{89} \mathrm{Zr}$ ) and consequently remarkably high specific activities in the range of $\mathrm{GBq} / \mu \mathrm{mol}$. This property is key for facilitating clinical translation since it avoids purification steps and would allow the injection of submicromolar concentrations of the therapeutic liposomal nanomedicine (microdosing), hence minimizing any potentially undesirable chemotherapeutic toxicity effects to patients from the imaging study. For example, the typical therapeutic dose of Doxil/Caelyx for a $70 \mathrm{~kg}$ individual contains approximately 546 $\mu$ mol of phospholipid, and a typical imaging dose for PET imaging a long-circulating tracer such as an antibody labeled with ${ }^{89} \mathrm{Zr}$ is $75 \mathrm{MBq}^{44}$ According to our experiments, such an amount of ${ }^{89} \mathrm{Zr}$ radioactivity, sufficient for human PET studies, could be loaded into a Doxil/Caelyx dose of just $0.034 \mu \mathrm{mol}$ of phospholipid, which is $6 \times 10^{-3} \%$ of the therapeutic dose and far below the accepted maximum value for microdosing (i.e., $1 \%$ of the therapeutic dose). According to our results, other combinations that would allow microdose PET clinical imaging under these conditions (i.e., those that achieve specific activities $\geq 14 \mathrm{MBq} / \mu$ mol phospholipid) would be ${ }^{89} \mathrm{Zr} /{ }^{52} \mathrm{Mn} /{ }^{64} \mathrm{Cu}-$ PLA, ${ }^{89} \mathrm{Zr}$-PLA-Na, ${ }^{89} \mathrm{Zr} /{ }^{52} \mathrm{Mn}$-PLAD, ${ }^{89} \mathrm{Zr}$-Doxil, and possibly ${ }^{52} \mathrm{Mn}$-Doxil.

The radiolabeling yields follow basic metal coordination chemistry principles as expected for the formation of the PET radiometal-drug complexes. Thus, RLYs were consistent with Pearson's hard and soft acid-base theory. Hence, the bisphosphonate-a highly anionic and oxygen-rich drugshowed high affinity for the two hard Lewis acids, $\mathrm{Zr}(\mathrm{IV})$ and $\mathrm{Mn}(\mathrm{II})$. On the other hand, $\mathrm{Cu}$ (II), a borderline Lewis acid, shows lower affinity for oxygen-based ligands. Doxorubicin, a nonanionic metal chelator, consequently showed lower RLYs $\left({ }^{89} \mathrm{Zr},{ }^{52} \mathrm{Mn}\right)$ or no radiolabeling $\left({ }^{64} \mathrm{Cu}\right)$ at the concentration ranges tested. The presence of $\mathrm{Na}^{+}$as intraliposomal counterion for alendronate in PLA-Na blocks radiolabeling with ${ }^{64} \mathrm{Cu}$, compared to the same formulation with $\mathrm{NH}_{4}^{+}$as counterion (PLA) (Figure 1D). This result could be explained by the chemical nature of $\mathrm{Na}^{+}$, a coordinating metal ion and hard Lewis acid with strong affinity for oxygen donors. On the other hand, $\mathrm{NH}_{4}^{+}$, a nonmetallic cation unable to form coordination bonds with bisphosphonates, is not able to compete with the radiometal. We did not observe this effect with ${ }^{89} \mathrm{Zr}$ or ${ }^{52} \mathrm{Mn}$, most likely due to their higher oxophilicity and charge $(+4$ and $+2 v s+1)$, which successfully compete with the $\mathrm{Na}^{+}$ion.
Collectively, liposomes radiolabeled using this method showed excellent stability in human serum at $37{ }^{\circ} \mathrm{C}$ over 48 $\mathrm{h}\left(93.8 \pm 4.6 \% ; n=10 ;{ }^{89} \mathrm{Zr},{ }^{52} \mathrm{Mn}\right.$, and $\left.{ }^{64} \mathrm{Cu}\right)$ and $72 \mathrm{~h}(92.8$ $\pm 6.4 \% ; n=8 ;{ }^{89} \mathrm{Zr}$ and $\left.{ }^{52} \mathrm{Mn}\right)$. These compare favorably to other reported radiolabeled liposomes and, importantly, match the circulation half-lives of current long-circulating liposomal nanomedicines in the clinic (i.e., $15-30 \mathrm{~h}$ in rodent; $50-80 \mathrm{~h}$ in humans). The human serum stability results showed metal and drug dependency, supporting our hypothesis and providing "perfect matched pairs" to maximize stability (e.g., ${ }^{89} \mathrm{Zr} /{ }^{52} \mathrm{Mn}$ and ammonium alendronate; ${ }^{89} \mathrm{Zr}$ and sodium alendronate; ${ }^{52} \mathrm{Mn}$ and doxorubicin). Our studies also suggest that a requirement to achieve high in vitro serum stabilities with a given PET radiometal using our method is to achieve radiolabeling yields of $>60 \%$ in the presence of $c a .1 \mu \mathrm{mol}$ encapsulated liposomal drug.

The in vivo studies with ${ }^{89} \mathrm{Zr}$-PLA and ${ }^{64} \mathrm{Cu}$-PLA in the 3E. $\Delta$.NT mammary carcinoma and SKOV-3 ovarian cancer models, respectively, showed the expected pharmacokinetics and biodistribution of stealth liposomes (i.e., long circulation time, high tumor uptake, and metabolism via the RES), confirming the utility of this radiolabeling technique to track liposomal nanomedicines in vivo with different PET isotopes over a long period of time. The high uptake values in both tumors $(6.7 \pm 3.2 \% \mathrm{ID} /$ tumor at $72 \mathrm{~h}$ p.i. in $3 \mathrm{E} . \Delta . \mathrm{NT}$ model and $7.4 \pm 0.8 \% \mathrm{ID} /$ tumor at $48 \mathrm{~h}$ p.i. in SKOV-3 model) compare favorably to the recent median value of $0.7 \% \mathrm{ID} /$ tumor from a multivariate analysis on the compiled data on this field reported recently by Wilhelm et al. ${ }^{45}$ An unexpected finding during the ${ }^{89} \mathrm{Zr}$-PLA studies was a high uptake in the uterus of NSG mice. The fact that we did not detect such uptake in the ${ }^{64} \mathrm{Cu}$-PLA study in female SCID-Beige mice leads us to hypothesize that this result is specific to NSG mice and could be due high levels of vascularization, blood flow, and permeability in this strain, and further experiments would be required to confirm this hypothesis. Nonetheless, it is only by labeling and imaging nanomedicines at the whole body level that we can identify unexpected areas of uptake such as this.

The multimodal (PET/SPECT/fluorescence) reporter-gene strategy used allowed us to sequentially image the same animals both in PET $\left({ }^{89} \mathrm{Zr}\right.$-PLA) and in SPECT $\left({ }^{99 \mathrm{~m}} \mathrm{Tc}\right.$-hNIS reporter gene) at different time points and hence identify the location of viable cancer cells-including spontaneous metastases-and ${ }^{89} \mathrm{Zr}$-PLA in tissues. We found consistent colocalization in the viable tissue areas of primary tumors but also a high degree of heterogeneity within these areas. Fluorescence histological studies strongly suggest that this result is related to different levels of vascularization within the tumor (which do not always colocalize with areas of high density of viable hNIS-expressing cancer cells) and to the well-known EPR mechanism of tumor uptake of stealth nanoparticles.

In addition, metastastic tissues (lymph nodes and lung metastases) also showed a significant high uptake of ${ }^{89} \mathrm{Zr}$-PLA compared to controls, possibly driven by a higher level of microvascularization and EPR effect. To the best of our knowledge, EPR-driven uptake of liposomal nanomedicines in metastatic lymph nodes has not been observed before in small animal studies using nuclear imaging. There is, however, precedent from clinical studies. Thus, using a DTPA-loaded stealth liposome labeled with the SPECT isotope ${ }^{111} \mathrm{In}$, Harrington et al. detected metastatic lymph nodes in breast cancer and head and neck patients. ${ }^{7}$ By using PET-labeled 
nanomedicines and technology, such as the one reported here, these and smaller metastatic lesions in lymph nodes and other organs will be detected with better sensitivity and spatial resolution.

Our strategy has potential limitations for clinical translation. The first one, which applies to all radioactivity-based imaging agents with long circulation times and isotopes with long radiation half-lives, is patient radiation dose. Based on our animal imaging study with ${ }^{89} \mathrm{Zr}$-PLA, we have estimated a human mean radiation dose of $0.9 \pm 0.2 \mathrm{mSv} / \mathrm{MBq}$. This is a high radiation dose and would limit the number of times a patient may undergo such an imaging study, but it is worth mentioning that there may be a significant error associated with this estimation as a result of scaling the data from mouse to man, and recent reports from clinical immuno-PET studies with ${ }^{89} \mathrm{Zr}$-labeled antibodies have calculated radiation doses close to this value (e.g., up to $0.7 \mathrm{mSv} / \mathrm{MBq}){ }^{44}$ In addition, it is expected that future improvements in clinical PET technology may allow the detection of lower amounts of radioactivity, by as much as 40 -fold, and hence $1 / 40$ th the radiation dose to patients. ${ }^{44,46}$ Another limitation of our method is the requirement of a drug with chelating properties. However, since many drugs contain well-established metal chelator motifs and intraliposomal drug concentrations are very high $\left(10^{-1} \mathrm{M}\right.$ range), we believe that a great number of current and future liposomal drugs (Figure 1A and Figure S1), such as those studied here, will be amenable for efficient radiolabeling without modification, thus enabling the development of a powerful theranostic tool.

\section{CONCLUSIONS}

In summary, we have developed a simple and efficient method for radiolabeling preformed liposomal nanomedicines that contain a metal-chelating drug such as an aminobisphosphonate with metallic PET isotopes. As expected from the proposed radiometal-drug interaction, the drugs tested (alendronate and doxorubicin) have different affinities to the metals explored in this study $\left({ }^{89} \mathrm{Zr},{ }^{52} \mathrm{Mn}\right.$, and $\left.{ }^{64} \mathrm{Cu}\right)$, and the labeling yields and in vitro stabilities obtained are in accordance with the expected metal-ligand affinities from basic coordination chemistry principles. Radiolabeled liposomes containing a bisphosphonate showed excellent human serum stabilities $(\geq 95 \%)$ with all radiometals tested, which is consistent with the strong chelating properties of these molecules. Liposomes that contain a weaker chelator such as doxorubicin showed a higher affinity and stability with ${ }^{52} \mathrm{Mn}$. To demonstrate the feasibility of this method in vivo, we used preclinical PET-CT to study the biodistribution and pharmacokinetics of a bisphosphonateloaded PEGylated liposome (PLA) radiolabeled with ${ }^{89} \mathrm{Zr}$ and ${ }^{64} \mathrm{Cu}$ in two different tumor models (breast and ovarian cancer), showing the expected biodistribution of stealth liposomes and a high uptake in primary tumors (both models) and lymph node/lung metastases (breast cancer model only). Recent work by Pérez-Medina et al. have used a PET nanoreporter technology to demonstrate that PET-radiolabeled nanoparticles can predict the efficacy of nanomedicinal therapies in animal models. ${ }^{22}$ Hence, we foresee that the method described here may provide a powerful developmental theranostic tool for many current and future liposomal drugs and will allow the study of their biodistribution prior to treatment for patient selection. We expect this work may facilitate the inclusion of a pretreatment (and possibly on- treatment) imaging stage for the improvement of the clinical value of liposomal drugs that encapsulate metal-chelating drugs.

\section{METHODS}

Materials and Instrumentation. Reagents and materials were obtained from commercial sources and used as received unless otherwise noted. All tools for molecular biology were from NEB (Hitchin, UK). Mowiol was from ICN (Costa Mesa, CA, US). ${ }^{64} \mathrm{Ni}$ (99.6\% isotopically enriched) was purchased from CK GAS Products Ltd. (Hampshire, UK). Organic solvents were of HPLC grade. Water (Type I, 18.2 MS.cm) was obtained from an ELGA Purelab Option-Q system. For TLC studies, ITLC-SG strips (Agilent, UK) or $0.5 \times 10$ $\mathrm{cm}$ silica gel 60 F-254 aluminum-backed plates (Merck KGaA, Germany) were used. TLC/ITLC plates were scanned with a MiniScan TLC scanner equipped with a FC3600 detector optimized for the detection of $\beta^{+}$particles (Lablogic, UK). Radioactivity in samples was measured with a CRC-25R dose calibrator (Capintec, USA) or a 1282 CompuGamma $\gamma$ counter (LKB Wallac, Finland). Millex IC $0.22 \mu \mathrm{m}$ (13 mm) hydrophilic PTFE filters (Millipore, USA) were used throughout this study. Size-exclusion chromatography was performed with a GE ÄKTA Explorer system using PBS as eluent. Dynamic light scattering and $\zeta$-potential measurements were performed with a Zetasizer Nano ZS instrument (Malvern Instruments, UK) at $25^{\circ} \mathrm{C}$. Human serum was obtained from a healthy volunteer and filtered through a $0.2 \mu \mathrm{m}$ filter before use.

Liposome Components and Sources. The following components were used: hydrogenated soybean phosphatidylcholine (HSPC) (Lipoid, Germany), methoxypolyethylene glycol distearoyl phosphatidylethanolamine (mPEG2000-DSPE) (Biolab, Jerusalem, Israel), cholesterol (Chol) (Sigma, St. Louis, MO), alendronic acid (Teva, Israel, and Tokyo Chemical Industry Co Ltd., Japan), doxorubicin (Teva, Israel), PEGylated liposomal doxorubicin (Janssen Pharmaceuticals, NJ, USA, commercial name Doxil or Caelyx), mitomycin C prodrug (MLP) conjugate: 2,3-(distearoyloxy)propane1-dithio-4'-benzyloxycarbonyl-MMC (Aptuit-Laurus, Hyderabad, India).

Antibodies. Mouse monoclonal anti-CD31 and anti-GAPDH antibodies were purchased from Abcam (Cambridge, UK) and GeneTex (Hsinchu City, Taiwan R.O.C.), respectively. The rabbit polyclonal anti-NIS antibody SJ1 was from Imanis Life Sciences (Rochester, MN, US). All fluorescent secondary antibodies conjugated to either $\mathrm{Cy} 3$ or $\mathrm{Cy} 5$ were from Jackson Immunoresearch (West Grove, PA, US). Secondary anti-rabbit and anti-mouse antibodies conjugated to horseradish peroxidase (HRP) for immunoblotting were purchased from Dako (Thetford, UK).

Radionuclides. ${ }^{89} \mathrm{Zr}$. No-carrier-added zirconium-89 (radionuclidic purity $>99.9 \%$ ) was purchased from PerkinElmer and produced at the BV Cyclotron, Amsterdam. Solutions were received and stored as $\left.\mathrm{H}_{4}\left[{ }^{89} \mathrm{Zr} \text { (oxalate }\right)_{4}\right]$ in aqueous oxalic acid $(1 \mathrm{M})$ and were titrated with $0.5 \mathrm{M}$ ammonium acetate until $\mathrm{pH} \mathrm{6-7}$ (measured using $\mathrm{pH}$ strips), just before use. Specific activity: $\geq 150 \mathrm{GBq} / \mu$ mol versus DFO titration.

${ }^{52} \mathrm{Mn}$. ${ }^{52} \mathrm{Mn}$ was produced at The Hevesy Laboratory at the Technical University of Denmark based upon modifications to the methods presented by Graves et al. ${ }^{47}$ Briefly, natural chromium powder (100-325 mesh $99.99 \%$, Alfa Aesar) was pressed into a silver backing and bombarded with $90^{\circ}$ incident protons at $16 \mathrm{MeV}$ and 20 $\mu \mathrm{A}$ for $3 \mathrm{~h}$ on a GE PETtrace cyclotron. Following irradiation, the irradiated chromium target was dissolved in concentrated hydrochloric acid and diluted into ethanol. ${ }^{52} \mathrm{Mn}$ was concentrated and purified from the bulk chromium by three sequential column extractions and elutions from AG1x8 (Biorad) strong anion exchange resin, ultimately providing ${ }^{52} \mathrm{MnCl}_{2}$ in $2 \mathrm{~mL}$ of $0.1 \mathrm{M} \mathrm{HCl}$. This solution was carefully titrated before use with a $0.5 \mathrm{M}$ ammonium acetate solution until the $\mathrm{pH}$ was 7 . Specific activity: $2.6 \mathrm{GBq} / \mu \mathrm{mol}$ versus DOTA titration, cold trace metals present $\left(\mathrm{ng} / \mathrm{MBq}\right.$ of $\left.{ }^{52} \mathrm{Mn}\right): \mathrm{Cr}=60, \mathrm{Cu}=9, \mathrm{Co}=4, \mathrm{Fe}$ $=43, \mathrm{Mn}=2.4$.

${ }^{64} \mathrm{Cu} .{ }^{64} \mathrm{Cu}$ was produced at the PET Imaging Centre, St. Thomas' Hospital, London, UK, by proton bombardment of $10-15 \mathrm{mg}$ of ${ }^{64} \mathrm{Ni}$ 
(99.6\% isotopically enriched, CK GAS products Ltd., Hampshire, $\mathrm{UK})$, electroplated onto a gold disc at $25 \mu \mathrm{A}$ for $4-6 \mathrm{~h}$ in a CTI RDS $11211 \mathrm{MeV}$ cyclotron using purpose-built targetry. Purification of ${ }^{64} \mathrm{Cu}$ was undertaken using established procedures. ${ }^{48}$ Radionuclidic purity was confirmed by $\gamma$-ray spectroscopy (Ortec DSPEC Plus HPGe $\gamma$-ray spectrometer) to be $>99 \% .{ }^{64} \mathrm{CuCl}_{2}$ was obtained in $\mathrm{HCl}$ solution and transformed into ${ }^{64} \mathrm{Cu}(\mathrm{OAc})_{2}$ by evaporation of the solution to a small volume and addition of small volumes of $0.5 \mathrm{M}$ ammonium acetate buffer ( $\mathrm{pH} 5.5)$, until the $\mathrm{pH}$ reached that of the buffer. Purity was confirmed by TLC $\left(R_{f}=0.66\right)$ with silica gel plates using $15 \mathrm{mM}$ EDTA in $10 \%$ ammonium acetate $/ \mathrm{MeOH}(50 / 50)$ as the mobile phase. Specific activity: ca. $11 \mathrm{GBq} / \mu$ mol versus TETA titration. ${ }^{48}$

${ }^{99 \mathrm{~m}} \mathrm{TCO}_{4}{ }^{-} .{ }^{99 \mathrm{~m}} \mathrm{Tc}$-pertechnetate in saline was eluted from a Drytec generator (GE Healthcare, Amersham, UK) from the Radiopharmacy at Guy's and St. Thomas' Hospital Nuclear Medicine Department at King's College London, UK.

Synthesis of PEGylated Liposomal Alendronate (PLA). Liposomes were prepared by the standard method of ethanol injection into an aqueous buffer, followed by extrusion through polycarbonate membrane filters down to $0.05 \mu \mathrm{m}$ pore size. The lipid components, HSPC, mPEG-DSPE, and Chol at mol ratios of 55, 40, and 5\%, respectively, were weighed and dissolved in ethanol. The buffer was a solution of $250 \mathrm{mM}$ alendronic acid (ALD) dissolved in $\mathrm{H}_{2} \mathrm{O}$ and adjusted to $\mathrm{pH} 6.0$ with $25 \%$ ammonium hydroxide at $60{ }^{\circ} \mathrm{C}$ to form a salt of $\mathrm{ALD}\left(\mathrm{NH}_{4}\right)_{2}$. The resulting liposomes were then processed by serial size extrusion in a high-pressure extruder device (Lipex Biomembranes, Vancouver, BC) with temperature control at $60^{\circ} \mathrm{C}$ through filters with pore sizes from 1 to $0.05 \mu \mathrm{m}$. Non-encapsulated ALD was removed by dialysis against a buffer of $5 \%$ dextrose with 15 $\mathrm{mM}$ histidine, $\mathrm{pH}$ 7.0, followed by passage over a Dowex anion exchange resin. The liposomes were sterilized by filtration through $0.22 \mu \mathrm{M}$ filters and stored in Vacutainer tubes at $4{ }^{\circ} \mathrm{C}$. Phospholipid (PL) and ALD content were determined after Folch extraction (8:4:3 $\mathrm{CHCl}_{3} / \mathrm{MeOH} / \mathrm{H}_{2} \mathrm{O}$ or sample) where the lower lipophilic phase contains the organic phosphate (PL) and the upper phase contains the inorganic phosphate (ALD). Samples of each phase were assayed by the Bartlett method to determine phosphorus. ALD quantification based on phosphorus content was confirmed at the Nanotechnology Characterization Laboratory (NCL, Frederick, MD, USA).

Synthesis of PEGylated Liposomal Alendronate-Doxorubicin (PLAD). PLAD was synthesized using a gradient-induced loading of doxorubicin (Dox): PLA, prepared as described above, was incubated with a solution of $10 \mathrm{mg} / \mathrm{mL}$ of Dox in $5 \%$ dextrose at ALD-Dox molar ratios ranging between 2 and 0.5 . The incubation was with gentle shaking for $60 \mathrm{~min}$ at a temperature of $60^{\circ} \mathrm{C}$, followed by ice-water cooling immediately upon end of incubation. The resulting liposome suspension was passed through a Dowex cation exchange resin to remove any non-encapsulated Dox and was sterilized using $0.22 \mu \mathrm{m}$ filters. Dox concentration was measured spectrophotometrically by absorbance at $480 \mathrm{~nm}$ after dilution and disruption of the liposomes in acidified $(0.075 \mathrm{~N} \mathrm{HCl}) 10: 90 \mathrm{H}_{2} \mathrm{O} / t-\mathrm{BuOH}$ solution. The final concentration of Dox in the formulation was adjusted to 2.0 $\mathrm{mg} / \mathrm{mL}$ by further dilution with the dialysis buffer $(5 \%$ dextrose $/ 15$ $\mathrm{mM}$ histidine). Dox quantification was confirmed at the Nanotechnology Characterization Laboratory (NCL, Frederick, MD, USA).

Synthesis of PROMITIL. PEGylated liposomal mitomycin C lipidbased prodrug (PROMITIL) was prepared and characterized as previously reported ${ }^{49}$ and provided by Lipomedix Pharmaceuticals Ltd.

Synthesis of PROMITIL-ALD. PEGylated liposomal mitomycin C lipid-based prodrug containing encapsulated ALD (PROMITIL-ALD) was prepared as PROMITIL ${ }^{49}$ with the same lipids but using a HSPC/ Chol/PEG-DSPE/MLP 55/30/5/10 molar ratio and using a $155 \mathrm{mM}$ $\operatorname{ALD}\left(\mathrm{NH}_{4}\right)_{2}$ buffer solution ( $\mathrm{pH}$ 6.5) during liposome formation. The resulting liposomes were then processed by serial size extrusion in a high-pressure extruder device (Lipex Biomembranes, Vancouver, BC) with temperature control at $60^{\circ} \mathrm{C}$ through filters with pore sizes from 1 to $0.05 \mu \mathrm{m}$. Non-encapsulated ALD was removed by dialysis against a buffer of $5 \%$ dextrose in $15 \mathrm{mM}$ HEPES, $\mathrm{pH}$ 7.0. The liposomes were sterilized by filtration through $0.22 \mu \mathrm{M}$ filters and stored in Vacutainer tubes at $4{ }^{\circ} \mathrm{C}$. Phospholipid and ALD content were determined after Folch extraction $\left(8: 4: 3 \mathrm{CHCl}_{3} / \mathrm{MeOH} / \mathrm{H}_{2} \mathrm{O}\right.$ or sample) where the lower lipophilic phase contains the organic phosphate (PL) and the upper phase contains the inorganic phosphate (ALD). Samples of each phase were assayed by the Bartlett method to determine phosphorus. The batch used for these studies contained $30.2 \mu \mathrm{mol} / \mathrm{mL}$ PL, $2.2 \mathrm{mg} / \mathrm{mL} \mathrm{ALD}$, and $6.7 \mathrm{mg} / \mathrm{mL}$ MLP and showed a mean hydrodynamic size of $111 \mathrm{~nm}(\mathrm{PDI}=0.088)$ by DLS.

Synthesis of ${ }^{89} \mathrm{Zr}$-ALD. $\mathrm{H}_{4}{ }^{[89} \mathrm{Zr}$ (oxalate) $\left.{ }_{4}\right]$ in aqueous $1 \mathrm{M}$ oxalic acid $(10 \mu \mathrm{L}, 14 \mathrm{MBq})$ was mixed with $360 \mu \mathrm{g}$ of ALD in $300 \mu \mathrm{L}$ of PBS. The $\mathrm{pH}$ of the solution was increased to 7 by addition of $10 \mu \mathrm{L}$ of a $1 \mathrm{M} \mathrm{Na}_{2} \mathrm{CO}_{3}$ solution and the mixture heated at $50^{\circ} \mathrm{C}$ for $5 \mathrm{~min}$. The formation of the complex was confirmed by ITLC-SG strips with a $20 \mathrm{mM}$ sodium citrate mobile phase. Using this system, ${ }^{89} \mathrm{Zr}$-ALD has a $R_{f}=0$, whereas $\left.\mathrm{H}_{4}\left[{ }^{89} \mathrm{Zr} \text { (oxalate) }\right)_{4}\right]$ has a $R_{f}=0.9$.

Radiolabeling of Liposomes. To radiolabel the liposomes (PLACEBO, PLA, PLA-Na, PLAD, Doxil, PROMITIL, PROMITILALD), an aliquot of the radiometal-ionophore solution (vide infra) was mixed with a double volume of the liposomes at the desired concentration in PBS or saline (chelexed) and incubated at $50{ }^{\circ} \mathrm{C}$ for 30 min with constant shaking. Specific details including concentrations of liposomes and radiometal-ionophore complexes, as well as radiolabeling yields and maximum specific activities, are shown in Table S4. To calculate the radiolabeling yield and/or purify the radiolabeled liposomes, the mixture (or an aliquot) was loaded into a Sephadex-G25 minitrap column (GE Healthcare Life Sciences, UK) using the manufacturer's protocol and eluted using PBS in $250 \mu \mathrm{L}$ fractions. Fractions containing the liposomes (first $750 \mu \mathrm{L}$ ) and column were measured for radioactivity to provide the radiolabeling yield. If required, radiolabeled liposomes can be concentrated using Vivaspin 500 30K MWCO spin filters (GE Healthcare, UK).

Synthesis of lonophore-Radiometal Complexes. ${ }^{64} \mathrm{Cu}(2 \mathrm{HQ})_{2}$. This complex has been reported previously ${ }^{14}$ but was synthesized by a different route. To make the stock solution of the ionophore (2HQ), 3 $\mathrm{mg}$ was dissolved in $300 \mu \mathrm{L}$ of absolute $\mathrm{EtOH}$ (assisted by mild heating), and this solution was subsequently mixed with $300 \mu \mathrm{L}$ of a $0.5 \mathrm{M}$ ammonium acetate buffer $\mathrm{pH}$ 5.5. To form the ${ }^{64} \mathrm{Cu}$-ionophore complex, $60 \mu \mathrm{L}$ of the $2 \mathrm{HQ}$ stock solution (300 $\mu \mathrm{g}$ of ionophore) was mixed with $200 \mu \mathrm{L}$ of the buffered ${ }^{64} \mathrm{Cu}(\mathrm{OAc})_{2}$ solution, and this mixture was incubated at room temperature for $15 \mathrm{~min}$. Quality control was performed using a 1-octanol $/ \mathrm{H}_{2} \mathrm{O}$ solvent extraction method and calculating its partition coefficient. The same measurement was carried out with unchelated ${ }^{64} \mathrm{Cu}$ as a control. ${ }^{64} \mathrm{Cu}(2 \mathrm{HQ})_{2}$ has a $\log P_{\text {octanol/water }}=0.91 \pm 0.07(n=3)$, whereas for unchelated buffered ${ }^{64} \mathrm{Cu}$, this value is $\log P_{\text {octanol } / \text { water }}=-0.11 \pm 0.12(n=3)$.

${ }^{89} \mathrm{Zr}(8 \mathrm{HQ})_{4} \cdot{ }^{89} \mathrm{Zr}(8 \mathrm{HQ})_{4}$ was synthesized and characterized following a previously published protocol. ${ }^{31}$

${ }^{52} \mathrm{Mn}(8 \mathrm{HQ})_{2}$. To make the stock solution of the ionophore, $3 \mathrm{mg}$ was dissolved in $300 \mu \mathrm{L}$ of absolute EtOH (assisted by mild heating) and subsequently mixed with $300 \mu \mathrm{L}$ of a $0.5 \mathrm{M}$ ammonium acetate solution $\mathrm{pH}$ 7. Thirty microliters of this solution $(150 \mu \mathrm{g}$ of ionophore) was mixed with $200 \mu \mathrm{L}$ of the buffered ${ }^{52} \mathrm{Mn}$ solution, and this mixture was incubated at room temperature for $15 \mathrm{~min}$. The $\mathrm{pH}$ of the reaction solution was tested to confirm it was 7. Quality control was performed using a 1-octanol $/ \mathrm{H}_{2} \mathrm{O}$ solvent extraction method and comparing with unchelated buffered ${ }^{52} \mathrm{Mn}$ as a control. ${ }^{52} \mathrm{Mn}(8 \mathrm{HQ})_{2}$ has a $\log P_{\text {octanol } / \text { water }}=0.69 \pm 0.25(n=3)$ compared to that of unchelated ${ }^{52} \mathrm{Mn}\left(\log P_{\text {octanol } / \text { water }}=0.07 \pm 0.04 ; n=3\right)$.

In Vitro Stability Studies in Human Serum. Radiolabeled liposomes were mixed with human serum $(10 \% \mathrm{v} / \mathrm{v})$ and incubated at $37{ }^{\circ} \mathrm{C}$ with gentle shaking for $48 \mathrm{~h}\left({ }^{64} \mathrm{Cu}\right)$ or $72 \mathrm{~h}\left({ }^{89} \mathrm{Zr},{ }^{52} \mathrm{Mn}\right)$. The stability was tested by injecting $0.5 \mathrm{~mL}$ of this mixture into a sizeexclusion chromatography column Superose 6 10/300 GL column (GE Healthcare, UK) at a flow rate of $0.5 \mathrm{~mL}$ PBS buffer/min. Using this system, liposomes elute as a single peak between fractions 8 and $11 \mathrm{~mL}$, and serum proteins elute as two main peaks between 15 and 25 $\mathrm{mL}$. Small molecules elute at fractions between 25 and $40 \mathrm{~mL}$. All fractions were $\gamma$-counted, and the column was monitored to confirm 
the absence of remaining activity. To measure the percentage of radiolabeled liposomes, the following formula was used:

$$
\begin{aligned}
\% \text { stable liposomes }= & \left(\text { counts } \min ^{-1}(\text { liposome fractions }) \times 100\right) \\
& /\left(\text { counts } \min ^{-1}(\text { liposome fractions })\right. \\
& + \text { counts } \min ^{-1}(\text { protein } \\
& + \text { small molecule fractions }))
\end{aligned}
$$

Cell Line Generation and Culture. MTLn3E mammary adenocarcinoma cells ${ }^{50,51}$ (a kind gift of Dr. E. Sahai, CRUK London Research Institute) were rendered more metastatic by overexpression of a desensitization-defective chemokine receptor CXCR4 mutant (truncation by the last 34 amino acids of its C-terminus) ${ }^{52,53}$ This highly metastatic cell line spontaneously spreads from orthotopically grown (mammary fat pad) primary tumors as recently demonstrated by whole-body in vivo cancer cell tracking. ${ }^{34}$ The cells were modified to stably express the human sodium iodide symporter (hNIS) fused to the fluorescent reporter TagRFP to enable multiscale multimodal in vivo cell tracking and ex vivo confocal fluorescence microscopy-based confirmation of the presence in harvested tissues. Briefly, the DNA of human NIS was amplified from cDNA by PCR and subcloned between the XhoI and EcoRI sites of pTagRFP-N1 (Evrogen, Moscow, Russia), yielding NIS C-terminally fused to TagRFP (NT). Primer sequences used for cloning of NIS-TagRFP were $5^{\prime}$-TTTCTCGAGGCCACCATGGAGGCCGTGGAGACCGGGGAACGG-3' (forward) and 5'CCGGAATTCCGAGGTTTGTCTCCTGCTGGTCTCG-3' (reverse). This construct was then subcloned into the retroviral expression vector pLPCX (Clontech, Saint-Germain-en-Laye, France) and confirmed by sequence analysis. Subsequently, retroviruses were produced by standard techniques in $293 \mathrm{~T}$ cells. Retroviruses were then used to infect MTLn3E. 34 -CXCR4 (3E. $\Delta$ ) cells. Stably NTexpressing cells lines were obtained post-infection by selection with puromycin $(2 \mu \mathrm{g} / \mathrm{mL})$ and subsequent FACS sorting (3E. $\Delta . \mathrm{NT})$.

MTLn3E cells and all derived cell lines were maintained in an atmosphere of $5 \% \mathrm{CO}_{2} / 95 \%$ air in $\alpha \mathrm{MEM}$ medium (Sigma, Gillingham, UK) supplemented with 5\% FBS (BioSera, Uckfield East, UK), with admixtures of selection antibiotics (puromycin and/or hygromycin) when necessary. 293T cells (ATCC) were grown in Dulbecco's modified MEM (Sigma) supplemented with $10 \%$ FBS in an atmosphere of $5 \% \mathrm{CO}_{2} / 95 \%$ air. In addition, all growth media contained $10 \mathrm{mg} / \mathrm{mL}$ L-glutamate, $100 \mathrm{U} / \mathrm{mL}$ penicillin, and $0.1 \mathrm{mg} /$ $\mathrm{mL}$ streptomycin. All cell lines were regularly ( $\leq 3$ month intervals) tested for mycoplasma (LookOut mycoplasma PCR detection kit, Sigma) and found to be negative throughout the study.

Flow Cytometry. For flow cytometric analysis, cells were harvested by short trypsinization, washed in PBS, and resuspended in PBS containing $2 \%(\mathrm{w} / \mathrm{v})$ bovine serum albumin (BSA) and $0.1 \%$ $(\mathrm{w} / \mathrm{v})$ ethylenediaminetetraacetic acid (EDTA). Cells were analyzed on a FACSCalibur flow cytometer (BD Bioscience) using the FL-1 (for GFP fluorescence) and FL-3 (for TagRFP fluorescence) channels.

Immunoblot Analysis. Briefly, cells were lysed in 1.5-fold sample buffer (1.5× LDS; $92.5 \mathrm{mM}$ Tris/ $\mathrm{HCl} \mathrm{pH} 8.5,0.75 \%(\mathrm{w} / \mathrm{w})$ lithium dodecylsulfate, $3.75 \%(\mathrm{w} / \mathrm{w})$ glycerol, $0.5 \mathrm{mM}$ EDTA, $0.2 \mathrm{mM}$ sodium vanadate, $10 \mathrm{nM}$ calyculin $\mathrm{A}, 50 \mathrm{mM}$ sodium fluoride, $1040 \mu \mathrm{M}$ AEBSF, $800 \mathrm{nM}$ aprotinin, $40 \mu \mathrm{M}$ bestain, $14 \mu \mathrm{M}$ E64 protease inhibitor, $20 \mu \mathrm{M}$ leupeptin, $15 \mu \mathrm{M}$ pepstatin $\mathrm{A}$ ), and the protein concentrations of the resulting lysates were determined using the BCA protein assay kit (Thermo Fisher, Waltham, MA, US). Equal amounts of protein were supplemented with $100 \mathrm{mM}$ DTT and $0.06 \mathrm{mM}$ Serva Blue G250 (Serva, Heidelberg, Germany), boiled, and subjected to electrophoresis using SDS-PAGE before being transferred to PVDF Immobilon membranes (EMD Millipore, Watford, UK). Membranes were blocked with $4 \%(\mathrm{w} / \mathrm{w})$ BSA in TBS-T for $30 \mathrm{~min}$, followed by incubation with the indicated primary antibody overnight at $4{ }^{\circ} \mathrm{C}$, washed four times with TBS-T, and incubated with the appropriate HRP-conjugated secondary antibody for $60 \mathrm{~min}$ at room temperature. The signal was detected with the ECL kit (Thermo Fisher, Waltham, MA, US) following the manufacturer's instructions.
Fluorescence Microscopy of Cells. Cells were grown on acidtreated glass coverslips to the desired cell densities and then fixed in $4 \%(\mathrm{w} / \mathrm{v})$ paraformaldehyde (PFA) for $15 \mathrm{~min}$. Subsequently, they were permeabilized with $0.25 \%(\mathrm{v} / \mathrm{v})$ Triton X-100, blocked with $1 \%$ $(w / v)$ BSA, stained for nuclei using Hoechst 33342 (Merck, Darmstadt, Germany), and mounted in Mowiol containing 2.5\% (w/v) Dabco as an antifade. Samples were imaged using a Nikon Eclipse Ti wide-field fluorescence microscope equipped with a Plan Apochromat 20×/0.5 NA air objective (Nikon, Tokyo, Japan).

In Vitro Radiotracer Uptake in NIS-Expressing Cells. On the day before the experiment, $5 \times 10^{5}$ cells per well were seeded in a 24well plate. Cells were washed with HBSS (containing $\mathrm{Ca}^{2+}$ and $\mathrm{Mg}^{2+}$ ), and $500 \mu \mathrm{L}$ of HBSS was added to each well. If blocking of NIS function was desired, $10 \mu \mathrm{L}$ of a $500 \mu \mathrm{M} \mathrm{NaClO}_{4}$ solution was added

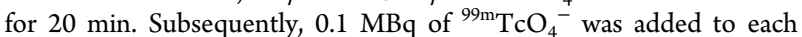
well and incubated for a further $30 \mathrm{~min}$. Supernatant of each well was removed, wells were washed three times with $1 \mathrm{~mL}$ of ice-cold HBSS, and then $500 \mu \mathrm{L}$ of $1 \mathrm{M} \mathrm{NaOH}$ was added to lyse the cells. The supernatant and washings of each well were pooled. Thirty microliters of each pooled supernatant/washings and cell lysate was measured with a $\gamma$ counter. The total activity in each pooled supernatant and cell lysate was calculated as follows:

$$
\begin{aligned}
\% \text { activity per well }= & \left(\text { counts } \min ^{-1}(\text { cell lysate OR supernatant })\right. \\
& \times 100) /\left(\text { counts } \min ^{-1}(\text { cell lysate })\right. \\
& \left.+ \text { counts } \min ^{-1}(\text { supernatant })\right)
\end{aligned}
$$

Animal Experiments. All animal experiments were approved by the UK Home Office and an ethical review panel, and all requirements dictated by UK legislation and the above committees were met. All immunocompromised mice were housed within filter-top cages in Scantainer units in approved facilities and given food and water ad libitum. All mice were anesthesized with isoflurane (3\% Vet Tech Solutions Ltd.) before injection of radiotracers.

3E.A.NT/NSG Tumor Model. Young adult (5-6 weeks old) female NOD scid gamma mice (NSG; genotype: NOD.Cg-Prkd $c^{\text {scid }} I l 2 r^{\text {tmllwjl }}$ / SzJ (005557)) were obtained from Charles River (UK) and housed for 2 days before tumor initiation. $3 \mathrm{E} . \Delta$.NT cells were trypsinized, washed with prewarmed HBSS (without $\mathrm{Ca}^{2+}$ and $\mathrm{Mg}^{2+}$ ), resuspended, counted, and aliquots of $5 \times 10^{5}$ cells in $50 \mu \mathrm{L}$ of HBSS were injected $\mathrm{s} / \mathrm{c}$ into the left mammary fat pad between nipples four and five. Once palpable, tumor volumes were measured with calipers using the following formula: $V=\pi / 6 l w d$, where $l$ is length, $w$ is width, and $d$ is depth. Imaging studies started 21 days after tumor inoculation.

SKOV-3/SCID-Beige Tumor Model. Young adult (5-6 weeks old) female SCID-Beige mice were obtained from Charles River (UK) and housed for 2 days before tumor initiation. SKOV3-ffLuc cells (Caliper) were trypsinized, washed with PBS (without $\mathrm{Ca}^{2+}$ and $\mathrm{Mg}^{2+}$ ), resuspended, counted, and aliquots of $2 \times 10^{6}$ cells in $50 \mu \mathrm{L}$ of PBS were injected $\mathrm{s} / \mathrm{c}$ into the left flank. Once palpable, tumor volumes were measured with calipers using the following formula: $V=\pi / 6 l w d$, where $l$ is length, $w$ is width, and $d$ is depth. Imaging studies started 72 days after tumor inoculation.

In Vivo Imaging and Analysis of Organ Distribution. PET/ SPECT Multimodal Study with 3E.A.NT/NSG Model. Mice were anesthetized with isofluorane (1.5-2\%) during all imaging sessions. ${ }^{89} \mathrm{Zr}$-PLA $(4.6 \pm 0.4 \mathrm{MBq}$ in $1.2 \mu \mathrm{mol}$ phospholipid; co-injected with empty liposomes to achieve a total injected lipid dose of $4 \mu \mathrm{mol}, 160$ $\mu \mathrm{L})$ or ${ }^{89} \mathrm{Zr}$-ALD $(4.4 \mathrm{MBq}, 100 \mu \mathrm{L})$ was injected i.v. at $t=0 \mathrm{~h}$, and imaging was performed after $10 \mathrm{~min}$ first by PET/CT (imaging of radiolabeled liposomal drugs), followed by injection of $100 \mu \mathrm{L}$ of a ${ }^{99} \mathrm{TcO}_{4}{ }^{-}$solution $(30 \mathrm{MBq})$ in saline (at $t=1 \mathrm{~h}$ ) and SPECT/CT imaging (imaging of tumor and metastases). PET/CT imaging was performed for $45 \mathrm{~min}$ on a nanoScan in vivo PET/CT preclinical imager (Mediso Medical Imaging Systems, Budapest, Hungary). SPECT/CT imaging was performed after $30 \mathrm{~min}$ after i.v. injection of ${ }^{99} \mathrm{TcO}_{4}{ }^{-}$using a NanoSPECT/CT Silver Upgrade (Mediso, Hungary) for $30 \mathrm{~min}$ with $1 \mathrm{~mm}$ collimators. PET-CT and SPECT-CT 
were repeated in the same sequence at $t=24,72(n=5)$, and $168 \mathrm{~h}(n$ = 1) for ${ }^{89} \mathrm{Zr}$-PLA or $t=24,72 \mathrm{~h}(n=2)$ for ${ }^{89} \mathrm{Zr}$-ALD.

PET-CT Study with SKOV-3/SCID-Beige Model. Mice were anesthetized with isofluorane (1.5-2\%) during all imaging sessions. ${ }^{64} \mathrm{Cu}$-PLA (14.2 MBq in $1.2 \mu \mathrm{mol}$ phospholipid; co-injected with empty liposomes to achieve a total injected lipid dose of $4 \mu \mathrm{mol}, 160$ $\mu \mathrm{L}$ ) was injected i.v. at $t=0 \mathrm{~h}$, and imaging was performed after 10 min by PET/CT (imaging of radiolabeled liposomal drugs) for $45 \mathrm{~min}$ on a nanoScan in vivo preclinical imager (Mediso, Hungary). PET-CT was repeated at $t=24,48 \mathrm{~h}(n=3)$.

All PET/SPECT/CT data sets were reconstructed using a Monte Carlo based full 3D iterative algorithm (Tera-Tomo, Mediso Medical Imaging Systems, Budapest, Hungary). Decay correction to time of injection was applied. CT images were obtained with $55 \mathrm{kVp}$ tube voltage, $1200 \mathrm{~ms}$ exposure time in 360 projections. All the images were analyzed using VivoQuant software (inviCRO, USA), which enables the co-registration of PET/SPECT/CT images and the delineation of regions of interest (ROIs) for quantification of activity (PET/SPECT) in specific organs. ROIs for different organs were defined in order to express uptake in each organ as percentage of injected dose per gram (\%ID/mL). Image-based quantification of the SPECT images was not reliable due to the presence of the high-energy $\gamma$ emissions of ${ }^{89} \mathrm{Zr}$ that introduced a high level of noise in the data.

Ex Vivo Biodistribution Studies. Biodistribution studies were carried out in accordance with British Home Office regulations governing animal experimentation. The mice from the imaging studies were used for the biodistribution studies. Mice under anesthesia were culled by cervical dislocation, and the organs of interest were dissected. Each sample was weighed and counted with a $\gamma$ counter (LKB compugamma), together with standards prepared from a sample of the injected material. If required, organs were weighted before freezing using OCT (VWR, Lutterworth, UK). The percent of injected dose per gram of tissue was calculated for each tissue type. The percent of injected dose per gram of ${ }^{89} \mathrm{Zr}$-PLA in metastatic lung tissue was obtained by calculating the average \%ID and mass of nonmetastatic lungs (from the ${ }^{89} \mathrm{Zr}$-PLA in non-tumor-bearing NSG mice study) and subtracting these average values to each value from the ${ }^{89} \mathrm{Zr}$-PLA study with tumor-bearing 3E. $\Delta . \mathrm{NT} / \mathrm{NSG}$ mice.

Fluorescence Microscopy of Tissues. Harvested tissues were stored at $-80{ }^{\circ} \mathrm{C}$ until most radioactivity was decayed and samples were considered safe to handle without radioprotection. Subsequently, $10 \mu \mathrm{m}$ thick tissue sections were cut using a cryostat and mounted on superfrost slides (VWR, Lutterworth, UK). Sections were fixed with 4\% PFA for $15 \mathrm{~min}$ at room temperature, blocked with $1 \%(\mathrm{w} / \mathrm{v}) \mathrm{BSA}$ (30 min), and stained with Hoechst $33342(1 \mu \mathrm{g} / \mathrm{mL}$ in PBS, $30 \mathrm{~min}$ ) and mounted in Mowiol containing 2.5\% (v/v) Dabco. For staining with anti-CD31, cut sections were treated with Fix \& Perm Solution B1000 (ADG, Kaumberg, Austria) and blocked with 1\% (w/v) BSA. Subsequently, samples were stained with the indicated primary antibodies in blocking buffer for $2 \mathrm{~h}$ at room temperature before being washed and incubated with appropriate fluorophore-conjugated secondary antibodies in blocking buffer for $45 \mathrm{~min}$ in the dark at room temperature. Samples were then stained with Hoechst $33342(1 \mu \mathrm{g})$ $\mathrm{mL}$ in PBS, $15 \mathrm{~min}$ ), washed, and mounted in Mowiol containing 2.5\% (w/v) Dabco as an antifade. Images were taken using a TCS SP5 (Leica, Wetzlar, Germany) confocal microscope equipped with PlanNeofluor $25 \times / 0.5$ NA and Plan-Apochromat $63 \times / 1.4$ NA objectives.

Autoradiography of Tissues. Harvested tissues were cut into $\sim 25 \mu \mathrm{m}$ thick sections using a cryostat and mounted on superfrost slides (VWR, Lutterworth, UK). Sections were fixed with 4\% PFA for $15 \mathrm{~min}$ at room temperature, washed, mounted in Mowiol, and exposed to a storage phosphor screen for either $2 \mathrm{~min}$ at $3 \mathrm{~h}$ postdissection to obtain the ${ }^{99 \mathrm{~m}} \mathrm{Tc}$ signal or $20 \mathrm{~min}$ at 5 days postdissection to obtain the ${ }^{89} \mathrm{Zr}$ signal. The storage phosphor screen was read out using a Typhoon 9200 imager (Amersham Biosciences, Amersham, UK) and analyzed using manufacturer's Image Quant software.

Human Absorbed Radiation Dosimetry Estimation. Human absorbed radiation dose (Medical Internal Raditaion Dose (MIRD) adult male and female standard models) was estimated using
OLINDA/EXM version 1.1 (Vanderbilt University, Nashville, TN, USA $)^{54}$ from the animal PET image-based time \% injected dose curves (non-decay-corrected) of the 3E. $\Delta . N T / N S G$ study with ${ }^{89} \mathrm{Zr}$-PLA. Preclinical data in the form of percentage uptake per gram of tissue were extrapolated to human percentage uptake per organ (standard MIRD model organ weights), using the method originally proposed by Kirschner et al. ${ }^{53}$ and subsequently applied by Chang et al. ${ }^{56}$ Organ masses used to scale from mouse to man were obtained from the ex vivo biodistribution experiment. The $\%$ injected dose values were rescaled with tumor uptake (for both models) and uterus uptake (for male only) excluded from the calculations.

Statistics. Student's $t$-tests were used to calculate $P$ values, and unless otherwise indicated, Prism software (GraphPad, La Jolla, CA/ USA) was used. Numbers in the text indicate means of pooled data \pm standard deviation unless otherwise stated.

\section{ASSOCIATED CONTENT}

\section{S Supporting Information}

The Supporting Information is available free of charge on the ACS Publications website at DOI: 10.1021/acsnano.6b05935.

Figures S1-S5 (drugs with chelating properties; characterization of in vivo traceable highly metastatic adenocarcinoma cells $-3 \mathrm{E} . \Delta ;{ }^{89} \mathrm{Zr}-\mathrm{ALD} / 3 \mathrm{E} . \Delta . \mathrm{NT} / \mathrm{NSG}$ in vivo study; ${ }^{64} \mathrm{Cu}-\mathrm{PLA} / \mathrm{SKOV}-3$ in vivo study; autoradiography of a selection of tumor slices from the mutimodal PET/SPECT study in the 3E. $\Delta . N T / N S G$ model; Tables S1-S4 with liposome physicochemical characterization data, biodistribution data, and radiolabeling reaction details; and a description of supporting video 1 (PDF)

Video S1: co-registration of PET and SPECT of representative tumor from the mutimodal PET/SPECT study in the 3E. $\Delta . \mathrm{NT} / \mathrm{NSG}$ model (MPG)

\section{AUTHOR INFORMATION}

\section{Corresponding Author}

*E-mail: rafael.torres@kcl.ac.uk.

\section{Author Contributions}

S.E. and R.R. developed and performed the radiosyntheses, characterization, and serum stability studies under the supervision of R.T.M.R. A.V. and G.F. developed the reporter-geneexpressing breast cancer model. A.V. conducted the multimodal in vivo imaging and histological studies; the synthesis and characterization of the liposomal nanomedicines was performed by H.S. under the supervision of A.G. A.C.P.P. and J.M. were responsible for the ovarian cancer model. G.S. produced and characterized ${ }^{52} \mathrm{Mn}$. J.B.T. performed preclinical imaging studies. I.S. and L.L. were responsible for image analysis and radiation dose estimation. P.B. supervised the development and radiochemistry with ${ }^{89} \mathrm{Zr}$ (oxinate) ${ }_{4}$. R.T.M.R. and A.G. conceived the study and supervised experiments, data analysis, and the writing/editing of the manuscript with contributions from all authors.

\section{Notes}

The authors declare the following competing financial interest(s): A.G. is founder and director of Lipomedix Pharmaceuticals, a start-up company which owns the rights to Promitil, which is one of the products discussed in this paper.

\section{ACKNOWLEDGMENTS}

We thank Dr. L. Meszaros for assistance with ${ }^{89} \mathrm{Zr}$ radiolabeling, Dr. Karen Shaw for ${ }^{64} \mathrm{Cu}$ production, and Mr. Stephen Clark and Dr. Kavitha Sunassee for preclinical imaging support. We 
are also grateful to Jenny Gorin, M.Sc. (Shaare Zedek MC and Lipomedix Pharmaceuticals, Ltd.) for excellent technical support with liposome manufacture and characterization. This work was funded by the King's College London and UCL Comprehensive Cancer Imaging Centre funded by the CRUK and EPSRC in association with the MRC and DoH (England) and by The Centre of Excellence in Medical Engineering funded by the Wellcome Trust and EPSRC under Grant No. WT $088641 / \mathrm{Z} / 09 / \mathrm{Z}$. The authors acknowledge financial support from the Department of Health via the National Institute for Health Research (NIHR) Biomedical Research Centre based at Guy's \& St Thomas' NHS Foundation Trust and King's College London. The views expressed are those of the authors and not necessarily those of the NHS, NIHR, or the Department of Health.

\section{REFERENCES}

(1) Farokhzad, O. C.; Langer, R. Impact of Nanotechnology on Drug Delivery. ACS Nano 2009, 3, 16-20.

(2) Wang, R.; Billone, P. S.; Mullett, W. M. Nanomedicine in Action: An Overview of Cancer Nanomedicine on the Market and in Clinical Trials. J. Nanomater. 2013, 2013, 1-12.

(3) Gabizon, A.; Catane, R.; Uziely, B.; Kaufman, B.; Safra, T.; Cohen, R.; Martin, F.; Huang, A.; Barenholz, Y. Prolonged Circulation Time and Enhanced Accumulation in Malignant Exudates of Doxorubicin Encapsulated in Polyethylene-glycol Coated Liposomes. Cancer Res. 1994, 54, 987-992.

(4) Jain, R. K.; Stylianopoulos, T. Delivering Nanomedicine to Solid Tumors. Nat. Rev. Clin. Oncol. 2010, 7, 653-664.

(5) Peer, D.; Karp, J. M.; Hong, S.; Farokhzad, O. C.; Margalit, R.; Langer, R. Nanocarriers as an Emerging Platform for Cancer Therapy. Nat. Nanotechnol. 2007, 2, 751-760.

(6) Prabhakar, U.; Maeda, H.; Jain, R. K.; Sevick-Muraca, E. M.; Zamboni, W.; Farokhzad, O. C.; Barry, S. T.; Gabizon, A.; Grodzinski, P.; Blakey, D. C. Challenges and Key Considerations of the Enhanced Permeability and Retention Effect for Nanomedicine Drug Delivery in Oncology. Cancer Res. 2013, 73, 2412-2417.

(7) Harrington, K. J.; Mohammadtaghi, S.; Uster, P. S.; Glass, D.; Peters, A. M.; Vile, R. G.; Stewart, J. S. W. Effective Targeting of Solid Tumors in Patients with Locally Advanced Cancers by Radiolabeled Pegylated Liposomes. Clin. Cancer Res. 2001, 7, 243-254.

(8) Petersen, A. L.; Hansen, A. E.; Gabizon, A.; Andresen, T. L. Liposome Imaging Agents in Personalized Medicine. Adv. Drug Delivery Rev. 2012, 64, 1417-1435.

(9) Kunjachan, S.; Ehling, J.; Storm, G.; Kiessling, F.; Lammers, T. Noninvasive Imaging of Nanomedicines and Nanotheranostics: Principles, Progress, and Prospects. Chem. Rev. 2015, 115, 1090710937.

(10) Lammers, T.; Rizzo, L. Y.; Storm, G.; Kiessling, F. Personalized Nanomedicine. Clin. Cancer Res. 2012, 18, 4889-4894.

(11) Boerman, O. C.; Laverman, P.; Oyen, W. J.; Corstens, F. H.; Storm, G. Radiolabeled Liposomes for Scintigraphic Imaging. Prog. Lipid Res. 2000, 39, 461-475.

(12) Marik, J.; Tartis, M. S.; Zhang, H.; Fung, J. Y.; Kheirolomoom, A.; Sutcliffe, J. L.; Ferrara, K. W. Long-circulating Liposomes Radiolabeled with $\left[{ }^{18} \mathrm{~F}\right]$ fluorodipalmitin $\left(\left[{ }^{18} \mathrm{~F}\right] \mathrm{FDP}\right)$. Nucl. Med. Biol. 2007, 34, 165-171.

(13) Seo, J. W.; Zhang, H.; Kukis, D. L.; Meares, C. F.; Ferrara, K. W. A Novel Method to Label Preformed Liposomes with ${ }^{64} \mathrm{Cu}$ for Positron Emission Tomography (PET) Imaging. Bioconjugate Chem. 2008, 19, 2577-2584.

(14) Petersen, A. L.; Binderup, T.; Rasmussen, P.; Henriksen, J. R.; Elema, D. R.; Kjær, A.; Andresen, T. L. ${ }^{64} \mathrm{Cu}$ Loaded Liposomes as Positron Emission Tomography Imaging Agents. Biomaterials 2011, 32, 2334-2341.

(15) Seo, J. W.; Qin, S.; Mahakian, L. M.; Watson, K. D.; Kheirolomoom, A.; Ferrara, K. W. Positron Emission Tomography
Imaging of the Stability of Cu-64 labeled Dipalmitoyl and Distearoyl Lipids in Liposomes. J. Controlled Release 2011, 151, 28-34.

(16) Li, S.; Goins, B.; Zhang, L.; Bao, A. Novel Multifunctional Theranostic Liposome Drug Delivery System: Construction, Characterization, and Multimodality MR, Near-Infrared Fluorescent, and Nuclear Imaging. Bioconjugate Chem. 2012, 23, 1322-1332.

(17) Kang, C. M.; Koo, H. J.; Lee, S.; Lee, K. C.; Oh, Y. K.; Choe, Y. S. ${ }^{64} \mathrm{Cu}$-Labeled Tetraiodothyroacetic acid-conjugated Liposomes for PET Imaging of Tumor angiogenesis. Nucl. Med. Biol. 2013, 40, 10181024.

(18) Seo, J. W.; Mahakian, L. M.; Tam, S.; Qin, S.; Ingham, E. S.; Meares, C. F.; Ferrara, K. W. The Pharmacokinetics of Zr-89 LabeledLiposomes Over Extended Periods in a Murine Tumor Model. Nucl. Med. Biol. 2015, 42, 155-163.

(19) Perez-Medina, C.; Abdel-Atti, D.; Zhang, Y.; Longo, V. A.; Irwin, C. P.; Binderup, T.; Ruiz-Cabello, J.; Fayad, Z. A.; Lewis, J. S.; Mulder, W. J. M.; Reiner, T. A Modular Labeling Strategy for In Vivo PET and Near-Infrared Fluorescence Imaging of Nanoparticle Tumor Targeting. J. Nucl. Med. 2014, 55, 1706-1711.

(20) Henriksen, J. R.; Petersen, A. L.; Hansen, A. E.; Frankær, C. G.; Harris, P.; Elema, D. R.; Kristensen, A. T.; Kjær, A.; Andresen, T. L. Remote Loading of ${ }^{64} \mathrm{Cu}^{2+}$ into Liposomes without the Use of Ion Transport Enhancers. ACS Appl. Mater. Interfaces 2015, 7, 2279622806.

(21) Lee, H.; Zheng, J.; Gaddy, D.; Orcutt, K. D.; Leonard, S.; Geretti, E.; Hesterman, J.; Harwell, C.; Hoppin, J.; Jaffray, D. A.; Wickham, T.; Hendriks, B. S.; Kirpotin, D. A Gradient-loadable (64)Cu-chelator for Quantifying Tumor Deposition Kinetics of Nanoliposomal Therapeutics by Positron Emission Tomography. Nanomedicine 2015, 11, 155-165.

(22) Perez-Medina, C.; Abdel-Atti, D.; Tang, J.; Zhao, Y.; Fayad, Z. A.; Lewis, J. S.; Mulder, W. J.; Reiner, T. Nanoreporter PET Predicts the Efficacy of Anti-cancer Nanotherapy. Nat. Commun. 2016, 7, 11838 .

(23) Emmetiere, F.; Irwin, C.; Viola-Villegas, N. T.; Longo, V.; Cheal, S. M.; Zanzonico, P.; Pillarsetty, N.; Weber, W. A.; Lewis, J. S.; Reiner, T. ${ }^{18}$ F-Labeled-Bioorthogonal Liposomes for In Vivo Targeting. Bioconjugate Chem. 2013, 24, 1784-1789.

(24) Abou, D. S.; Thorek, D. L. J.; Ramos, N. N.; Pinkse, M. W. H.; Wolterbeek, H. T.; Carlin, S. D.; Beattie, B. J.; Lewis, J. S. ${ }^{89} \mathrm{Zr}$-Labeled Paramagnetic Octreotide-Liposomes for PET-MR Imaging of Cancer. Pharm. Res. 2013, 30, 878-888.

(25) Silbernagel, R; Martin, C. H.; Clearfield, A. Zirconium(IV) Phosphonate-Phosphates as Efficient Ion-Exchange Materials. Inorg. Chem. 2016, 55, 1651-1656.

(26) Demoro, B.; Caruso, F.; Rossi, M.; Benítez, D.; González, M.; Cerecetto, H.; Galizzi, M.; Malayil, L.; Docampo, R.; Faccio, R.; Mombrú, Á. W.; Gambino, D.; Otero, L. Bisphosphonate Metal Complexes as Selective Inhibitors of Trypanosoma Cruzi Farnesyl Diphosphate Synthase. Dalton Trans. 2012, 41, 6468.

(27) Benzaid, I.; Monkkonen, H.; Stresing, V.; Bonnelye, E.; Green, J.; Monkkonen, J.; Touraine, J. L.; Clezardin, P. High Phosphoantigen Levels in Bisphosphonate-treated Human Breast Tumors Promote Vgamma9Vdelta2 T-cell Chemotaxis and Cytotoxicity In Vivo. Cancer Res. 2011, 71, 4562-4572.

(28) Gnant, M.; Mlineritsch, B.; Schippinger, W.; LuschinEbengreuth, G.; Pöstlberger, S.; Menzel, C.; Jakesz, R.; Seifert, M.; Hubalek, M.; Bjelic-Radisic, V.; Samonigg, H.; Tausch, C.; Eidtmann, H.; Steger, G.; Kwasny, W.; Dubsky, P.; Fridrik, M.; Fitzal, F.; Stierer, M.; Rücklinger, E.; Greil, R. Endocrine Therapy plus Zoledronic Acid in Premenopausal Breast Cancer. N. Engl. J. Med. 2009, 360, 679-691.

(29) Parente-Pereira, A. C.; Shmeeda, H.; Whilding, L. M.; Zambirinis, C. P.; Foster, J.; van der Stegen, S. J. C.; Beatson, R.; Zabinski, T.; Brewig, N.; Sosabowski, J. K.; Mather, S.; GhaemMaghami, S.; Gabizon, A.; Maher, J. Adoptive Immunotherapy of Epithelial Ovarian Cancer with V 9V 2 T Cells, Potentiated by Liposomal Alendronic Acid. J. Immunol. 2014, 193, 5557-5566. 
(30) McAfee, J. G.; Thakur, M. L. Survey of Radioactive Agents for In Vitro Labeling of Phagocytic Leukocytes. I. Soluble agents. J. Nucl. Med. 1976, 17, 480-487.

(31) Charoenphun, P.; Meszaros, L. K.; Chuamsaamarkkee, K.; Sharif-Paghaleh, E.; Ballinger, J. R; Ferris, T. J.; Went, M. J.; Mullen, G. E.; Blower, P. J. $\left[{ }^{89} \mathrm{Zr}\right]$ oxinate $_{4}$ for Long-term In Vivo Cell Tracking by Positron Emission Tomography. Eur. J. Nucl. Med. Mol. Imaging 2015, 42, 278-287.

(32) Gabizon, A. A.; Tzemach, D.; Horowitz, A. T.; Shmeeda, H.; Yeh, J.; Zalipsky, S. Reduced Toxicity and Superior Therapeutic Activity of a Mitomycin C Lipid-Based Prodrug Incorporated in Pegylated Liposomes. Clin. Cancer Res. 2006, 12, 1913-1920.

(33) Gabizon, A.; Shmeeda, H.; Barenholz, Y. Pharmacokinetics of Pegylated Liposomal Doxorubicin - Review of Animal and Human Studies. Clin. Pharmacokinet. 2003, 42, 419-436.

(34) Fruhwirth, G. O.; Diocou, S.; Blower, P. J.; Ng, T.; Mullen, G. E. A Whole-Body Dual-modality Radionuclide Optical Strategy for Preclinical Imaging of Metastasis and Heterogeneous Treatment Response in Different Microenvironments. J. Nucl. Med. 2014, 55, 686-694.

(35) Deri, M. A.; Zeglis, B. M.; Francesconi, L. C.; Lewis, J. S. PET Imaging with $\mathrm{Zr}-89$ : From Radiochemistry to the Clinic. Nucl. Med. Biol. 2013, 40, 3-14.

(36) Torres Martin de Rosales, R.; Tavare, R.; Glaria, A.; Varma, G.; Protti, A.; Blower, P. J. ${ }^{99 \mathrm{~m}}$ Tc-Bisphosphonate-Iron Oxide Nanoparticle Conjugates for Dual-Modality Biomedical Imaging. Bioconjugate Chem. 2011, 22, 455-465.

(37) Severin, G. W.; Jørgensen, J. T.; Wiehr, S.; Rolle, A.-M.; Hansen, A. E.; Maurer, A.; Hasenberg, M.; Pichler, B.; Kjær, A.; Jensen, A. I. The Impact of Weakly Bound ${ }^{89} \mathrm{Zr}$ on Preclinical Studies: Non-specific Accumulation in Solid Tumors and Aspergillus Infection. Nucl. Med. Biol. 2015, 42, 360-368.

(38) Shmeeda, H.; Amitay, Y.; Tzemach, D.; Gorin, J.; Gabizon, A. Liposome Encapsulation of Zoledronic Acid Results in Major Changes in Tissue Distribution and Increase in Toxicity. J. Controlled Release 2013, 167, 265-275.

(39) ElBayoumi, T. A.; Torchilin, V. P. Tumor-Targeted Nanomedicines: Enhanced Antitumor Efficacy In Vivo of DoxorubicinLoaded, Long-Circulating Liposomes Modified with Cancer-Specific Monoclonal Antibody. Clin. Cancer Res. 2009, 15, 1973-1980.

(40) Gabizon, A.; Goren, D.; Horowitz, A. T.; Tzemach, D.; Lossos, A.; Siegal, T. Long-Circulating Liposomes for Drug Delivery in Cancer Therapy: A Review of Biodistribution Studies in Tumor-Bearing Animals. Adv. Drug Delivery Rev. 1997, 24, 337-344.

(41) Chang, A. J.; DeSilva, R.; Jain, S.; Lears, K.; Rogers, B.; Lapi, S. ${ }^{89} \mathrm{Zr}$-Radiolabeled Trastuzumab Imaging in Orthotopic and Metastatic Breast Tumors. Pharmaceuticals 2012, 5, 79-93.

(42) Zeglis, B. M.; Mohindra, P.; Weissmann, G. I.; Divilov, V.; Hilderbrand, S. A.; Weissleder, R.; Lewis, J. S. Modular Strategy for the Construction of Radiometalated Antibodies for Positron Emission Tomography Based on Inverse Electron Demand Diels-Alder Click Chemistry. Bioconjugate Chem. 2011, 22, 2048-2059.

(43) Seo, J. W.; Mahakian, L. M.; Tam, S.; Qin, S.; Ingham, E. S.; Meares, C. F.; Ferrara, K. W. The Pharmacokinetics of Zr-89 Labeled Liposomes Over Extended Periods in a Murine Tumor Model. Nucl. Med. Biol. 2015, 42, 155-163.

(44) Borjesson, P. K. E.; Jauw, Y. W. S.; de Bree, R.; Roos, J. C.; Castelijns, J. A.; Leemans, C. R.; van Dongen, G. A. M. S.; Boellaard, R. Radiation Dosimetry of ${ }^{89} \mathrm{Zr}$-Labeled Chimeric Monoclonal Antibody U36 as Used for Immuno-PET in Head and Neck Cancer Patients. J. Nucl. Med. 2009, 50, 1828-1836.

(45) Wilhelm, S.; Tavares, A. J.; Dai, Q.; Ohta, S.; Audet, J.; Dvorak, H. F.; Chan, W. C. W. Analysis of Nanoparticle Delivery to Tumours. Nat. Rev. Mater. 2016, 1, 16014.

(46) Zhang, X. Z.; Zhou, J.; Wang, G. B.; Poon, J.; Cherry, S.; Badawi, R.; Qi, J. Y. Feasibility Study of Micro-Dose Total-Body Dynamic PET Imaging Using the EXPLORER Scanner. J. Nucl. Med. 2014, 55, 269.
(47) Graves, S. A.; Hernandez, R.; Fonslet, J.; England, C. G.; Valdovinos, H. F.; Ellison, P. A.; Barnhart, T. E.; Elema, D. R.; Theuer, C. P.; Cai, W.; Nickles, R. J.; Severin, G. W. Novel Preparation Methods of ${ }^{52} \mathrm{Mn}$ for ImmunoPET Imaging. Bioconjugate Chem. 2015, 26, 2118-2124.

(48) McCarthy, D. W.; Shefer, R. E.; Klinkowstein, R. E.; Bass, L. A.; Margeneau, W. H.; Cutler, C. S.; Anderson, C. J.; Welch, M. J. Efficient Production of High Specific Activity ${ }^{64} \mathrm{Cu}$ using a Biomedical Cyclotron. Nucl. Med. Biol. 1997, 24, 35-43.

(49) Amitay, Y.; Shmeeda, H.; Patil, Y.; Gorin, J.; Tzemach, D.; Mak, L.; Ohana, P.; Gabizon, A. Pharmacologic Studies of a Prodrug of Mitomycin C in Pegylated Liposomes (Promitil囚): High Stability in Plasma and Rapid Thiolytic Prodrug Activation in Tissues. Pharm. Res. 2016, 33, 686-700.

(50) Xue, C.; Wyckoff, J.; Liang, F.; Sidani, M.; Violini, S.; Tsai, K. L.; Zhang, Z. Y.; Sahai, E.; Condeelis, J.; Segall, J. E. Epidermal Growth Factor Receptor Overexpression Results in Increased Tumor Cell Motility In Vivo Coordinately with Enhanced Intravasation and Metastasis. Cancer Res. 2006, 66, 192-197.

(51) Neri, A.; Welch, D.; Kawaguchi, T.; Nicolson, G. L. Development and Biologic Properties of Malignant Cell Sublines and Clones of a Spontaneously Metastasizing Rat Mammary Adenocarcinoma. J. Natl. Cancer Inst. 1982, 68, 507-517.

(52) Vermeer, L. S.; Fruhwirth, G. O.; Pandya, P.; Ng, T.; Mason, A. J. NMR Metabolomics of MTLn3E Breast Cancer Cells Identifies a Role for CXCR4 in Lipid and Choline Regulation. J. Proteome Res. 2012, 11, 2996-3003.

(53) Futahashi, Y.; Komano, J.; Urano, E.; Aoki, T.; Hamatake, M.; Miyauchi, K.; Yoshida, T.; Koyanagi, Y.; Matsuda, Z.; Yamamoto, N. Separate Elements are Required for Ligand-Dependent and -Independent Internalization of Metastatic Potentiator CXCR4. Cancer Sci. 2007, 98, 373-379.

(54) Stabin, M. G.; Sparks, R. B.; Crowe, E. OLINDA/EXM: The Second-Generation Personal Computer Software for Internal Dose Assessment in Nuclear Medicine. J. Nucl. Med. 2005, 46, 1023-1027.

(55) Kirschner, A. S.; Ice, R. D.; Beierwaltes, W. H. Radiation Sosimetry of ${ }^{131}$ I-19-Iodocholesterol. J. Nucl. Med. 1973, 14, 713-717.

(56) Chang, C. H.; Chang, Y. J.; Lee, T. W.; Ting, G.; Chang, K. P. Dosimetric Evaluation of Nanotargeted ${ }^{188}$ Re-Liposome with the MIRDOSE3 and OLINDA/EXM Programs. Ann. Nucl. Med. 2012, 26, $419-425$. 